\title{
Results of the NeuroBlate System first-in-humans Phase I clinical trial for recurrent glioblastoma
}

\author{
Clinical article
}

\author{
Andrew E. Sloan, M.D., 1,2 Manmeet S. Ahluwalia, M.D., 3,4 \\ Jose Valerio-Pascua, M.D., ${ }^{3,5,6}$ Sunil Manjila, M.D., ${ }^{1}$ Mark G. Torchia, Ph.D., 7 \\ Stephen E. Jones, M.D., Ph.D., ${ }^{3,8}$ Jeffrey L. Sunshine, M.D., Ph.D., ${ }^{2,9}$ \\ Michael Phillips, M.D., ${ }^{3,8}$ Mark A. Griswold, Ph.D., 1,10 \\ Mark Clampitt, R.T.(R)(MR)(CT), ${ }^{9}$ CAThy Brewer, R.N., ${ }^{3}$ Jennifer Jochum, R.N., ${ }^{1,2}$ \\ Mary V. McGraw, ${ }^{3}$ Dawn Diorio, R.N., ${ }^{1,2}$ Gail Ditz, R.N., ${ }^{3}$ \\ AND GENE H. BARNETT, M.D., M.B.A..$^{2,3,5}$
}

${ }^{\prime}$ Brain Tumor \& Neuro-Oncology Center and Department of Neurosurgery, and ${ }^{9}$ Department of Radiology, University Hospitals Case Medical Center, Seidman Cancer Center; ${ }^{2}$ Case Comprehensive Cancer Center, and ${ }^{10}$ Department of Biomedical Engineering, Case Western Reserve University School of Medicine;

${ }^{3}$ Rose Ella Burkhardt Brain Tumor and Neuro-Oncology Center, Neurological Institute, Cleveland Clinic; ${ }^{4}$ Department of Solid Tumor Oncology, Taussig Cancer Institute, Cleveland Clinic; ${ }^{5}$ Department of Neurosurgery, Cleveland Clinic; ${ }^{8}$ Department of Neuroradiology, Radiology Institute, Cleveland Clinic, Cleveland, Ohio; ${ }^{6}$ Department of Neurosurgery, Cleveland Clinic Florida, Weston, Florida; and ${ }^{7}$ Department of Surgery, University of Manitoba, Winnipeg, Manitoba, Canada

Object. Laser interstitial thermal therapy has been used as an ablative treatment for glioma; however, its development was limited due to technical issues. The NeuroBlate System incorporates several technological advances to overcome these drawbacks. The authors report a Phase I, thermal dose-escalation trial assessing the safety and efficacy of NeuroBlate in recurrent glioblastoma multiforme (rGBM).

Methods. Adults with suspected supratentorial rGBM of 15- to 40-mm dimension and a Karnofsky Performance Status score of $\geq 60$ were eligible. After confirmatory biopsy, treatment was delivered using a rigid, gas-cooled, sidefiring laser probe. Treatment was monitored using real-time MRI thermometry, and proprietary software providing predictive thermal damage feedback was used by the surgeon, along with control of probe rotation and depth, to tailor tissue coagulation. An external data safety monitoring board determined if toxicity at lower levels justified dose escalation.

Results. Ten patients were treated at the Case Comprehensive Cancer Center (Cleveland Clinic and University Hospitals-Case Medical Center). Their average age was 55 years (range 34-69 years) and the median preoperative Karnofsky Performance Status score was 80 (range 70-90). The mean tumor volume was $6.8 \pm 5 \mathrm{~cm}^{3}$ (range 2.6-19 $\mathrm{cm}^{3}$ ), the percentage of tumor treated was $78 \% \pm 12 \%$ (range $57 \%-90 \%$ ), and the conformality index was $1.21 \pm 0.33$ (range 1.00-2.04). Treatment-related necrosis was evident on MRI studies at 24 and 48 hours. The median survival was 316 days (range 62-767 days). Three patients improved neurologically, 6 remained stable, and 1 worsened. Steroid-responsive treatment-related edema occurred in all patients but one. Three had Grade 3 adverse events at the highest dose.

Conclusions. NeuroBlate represents new technology for delivering laser interstitial thermal therapy, allowing controlled thermal ablation of deep hemispheric rGBM. Clinical trial registration no.: NCT00747253 (ClinicalTrials. gov).

(http://thejns.org/doi/abs/10.3171/2013.1.JNS1291)

\section{KEY WORDS $\quad$ laser interstitial thermal therapy $\bullet$ glioblastoma $\bullet \quad$ coagulation $\bullet$ brain tumor - clinical trial $\quad$ oncology}

\footnotetext{
Abbreviations used in this paper: DTI-FT = diffusion tensor imaging with fiber tracking; DVT = deep vein thrombosis; D1 = maximum width perpendicular to the laser probe; D2 = widest dimension perpendicular to both $\mathrm{D} 1$ and the probe; $\mathrm{GBM}=$ glioblastoma multiforme; KPS = Karnofsky Performance Status; LITT = laser interstitial thermal therapy; PE = pulmonary embolism; PTT = percentage of tumor treated; $\mathrm{rGBM}=$ recurrent GBM; SRS = stereotactic radiosurgery; $\mathrm{V}_{\mathrm{A}}=$ volume of nontumor treated at intended dose; $\mathrm{V}_{\mathrm{D}}=$ dosed volume; $\mathrm{V}_{\mathrm{I}}=$ intended volume; $\mathrm{V}_{\mathrm{T}}=$ target volume; $\mathrm{V}_{\mathrm{U}}=$ undosed volume.
}

7 He prognosis of patients with GBM remains dismal, with a median survival less than 15 months from the time of diagnosis. ${ }^{29}$ The median survival of patients with rGBM is only 3-5 months. Resection increases survival by only 8 weeks, ${ }^{1}$ but often is not feasible. Investigational treatments including systemic and local chemotherapy have not significantly improved survival and often have significant risks. Focal therapies such as brachytherapy ${ }^{4,27}$ and SRS ${ }^{27,30}$ have also had limited efficacy in selected patient populations. ${ }^{10,18,27}$ However, 
toxicity for brachytherapy has been high,$^{25}$ and the only randomized controlled study of radiosurgery (for newly diagnosed GBM) demonstrated no benefit, whereas the studies that did suggest benefit have been small, retrospective, single-institution studies providing level 4 evidence (http://www.cebm.net), which are marred by perceived selection bias. ${ }^{18}$ Thus, the utility of these modalities for the treatment of GBM has been controversial and has not yet been incorporated into currently accepted multiinstitutional cancer center guidelines for care. ${ }^{16}$

Laser interstitial thermal therapy is a minimally invasive technique for treating tumors percutaneously and has been used as an ablative treatment for glioma and other tumors for more than 2 decades. It may offer the benefit of surgery to brain tumor patients who are otherwise unsuitable for craniotomy. Treatments use low-powered thermal energy $y^{3,6-8,12,13,17,22-24}$ to create zones of coagulation (rather than vaporization) around the delivery fiber. Although complications such as hemiparesis and focal seizures have occasionally been described, other studies have demonstrated that strength and language function have occasionally improved, ${ }^{13}$ and increases in survival have also been suggested.22,23 However, several technical limitations of the devices have prevented widespread application of this technology. $7,8,22$ The most daunting of these has been the inability to precisely monitor the "dose" of LITT delivered to individual patients in real time. Previous descriptions of thermal energy application have primarily been based on theoretical a priori calculations of the energy required to treat a tumor based on tumor volume, without real-time monitoring or control of energy deposition to match specific geometry and heatconduction properties of the tumor. ${ }^{23,24}$ Others have used MR images in real time, but rely on a technique that identifies only tissues that die during the procedure. ${ }^{22}$ This underestimates the thermal damage in surrounding cells, which continues to develop for hours to days after lasing has been completed. An LITT technique using a 980$\mathrm{nm}$ diode laser and real-time thermometry ${ }^{3}$ was recently demonstrated for well-circumscribed brain metastases, but no such real-time approach has previously been demonstrated for primary brain tumors.

The NeuroBlate System (Monteris Medical, Inc.) incorporates several technological advances to overcome drawbacks seen with existing devices. NeuroBlate allows for conformal laser thermal coagulation of deep-seated brain tumors by using a side-firing laser probe equipped with software that predicts thermal tissue damage, in real time, by considering both temperature and duration of thermal exposure. The rotation and probe depth are controlled by the surgeon, allowing for "sculpting" of the thermal effect guided by real-time MRI thermography. We hypothesize that these technical advances to LITT will facilitate safer, more precise use of this technology to ablate GBMs and other lesions unsuitable for resection in a minimally invasive fashion. The goal of this Phase I trial was to evaluate the safety of NeuroBlate at 3 doses.

\section{Methods}

\section{Study Design}

This study was a prospective, multicenter, Phase I, sequential, thermal dose-escalation study conducted to evaluate the preliminary safety of, and techniques necessary for, the treatment of recurrent or progressive GBM using the NeuroBlate System. (The system was then called the AutoLITT system, but has since been rebranded as NeuroBlate by the company.) As in all Phase I studies, it was anticipated that toxicity might ensue-particularly at the highest dose. The main goal of the study was to evaluate the relationship between thermal dose, toxicity, and clinical efficacy. The study was approved by the institutional review board for the Case Comprehensive Cancer Center, the primary affiliate for clinical cancer research for both the Cleveland Clinic Foundation and University Hospitals-Case Medical Center. This study was performed under an investigational device exemption granted by the US FDA. This study was registered with the ClinicalTrials.gov database (http://www.clinicaltrials. gov/), and its registration no. is NCT00747253.

Adult patients with recurrent or progressive GBM in whom standard therapy (radiotherapy with or without chemotherapy) had failed were candidates for this study. A passive enrollment approach was used; study candidates were identified from the routine clinical populations present at the 2 sites. Participants were recruited after investigator review of the individual's clinical characteristics. Eligibility and exclusion criteria are summarized in Table 1. Informed consent was administered and patients were scheduled to receive the protocol treatments illustrated in Fig. 1.

The study design was a "k-in-a-row," modified upand-down dose-escalation design, as described by Ivanova et al. ${ }^{5}$ The goal of the design was to estimate the thermal dose that provides a $20 \%-30 \%$ probability of toxicity for an individual patient. It was anticipated that 3 thermal dose levels would probably be sufficient for the study. If any patient was unable to complete at least 14 days of follow-up for reasons not associated with the treatment or the procedure, then an additional patient would be recruited until at least 2 patients had been treated and had completed at least 14 days of follow-up at each dosing level. The intent-to-treat population was defined as those patients who had the laser probe inserted into the brain.

The 3 proposed thermal dosage levels were chosen based on preclinical data from in vivo porcine and canine models that included postprocedural histological analysis, using the approach discussed by Sapareto and Dewey. ${ }^{20}$ Table 2 lists the definitions of the chosen thermal doses used in this study.

The primary study end point was to evaluate the feasibility and safety of NeuroBlate application in treatment of rGBM. Safety for NeuroBlate application was defined as the absence of severe clinical toxicity within 14 days after the procedure. Severe toxicity was defined as toxicity associated with a drop of 20 or more points in the KPS score. The maximum therapeutic dose was to be estimated in this study.

Secondary study end points included toxicity evaluation, as estimated by brain edema that was not controlled by pharmacological interventions such as steroids, and other radiographic evidence of toxicity (for example, hemorrhage attributable to LITT or tissue damage outside of LITT-treated regions). Other secondary end points in- 
TABLE 1: Inclusion and exclusion criteria used in this study of patients with rGBMs*

\begin{tabular}{|c|c|}
\hline Inclusion Criteria & Exclusion Criteria \\
\hline $\begin{array}{l}\text { clinical \&/or radiographic suspicion of tumor recur/progression for which stereo- } \\
\text { tactic biopsy is deemed necessary to differentiate btwn tumor or Tx toxicity }\end{array}$ & $\begin{array}{l}\text { uncontrolled hypertension (systolic } \geq 180 \mathrm{~mm} \mathrm{Hg} \text { ), angina pectoris, } \\
\text { cardiac dysrhythmia, or recent intracranial hemorrhage }\end{array}$ \\
\hline resection of tumor is not immediately (w/in 30 days) indicated & pregnancy \\
\hline KPS score $\geq 60$ & abnormal absolute neutrophil count $\left(<1500 / \mathrm{mm}^{3}\right)$ or coagulopathy \\
\hline \multirow[t]{4}{*}{ pts must be competent to give informed consent } & $\begin{array}{l}\text { other concurrent medical or other condition (chronic or acute) that } \\
\text { in the opinion of the investigator may prevent safe participation or } \\
\text { otherwise render a patient ineligible for the study }\end{array}$ \\
\hline & inability or unwillingness to provide informed consent \\
\hline & $\begin{array}{l}\text { posterior fossa neoplasms or those w/ anticipated Tx margins that } \\
\text { will be w/in } 5 \mathrm{~mm} \text { of critical intracranial structures }\end{array}$ \\
\hline & multiple GBMs in which $>1$ has $a>15-\mathrm{mm}$ cross-sectional dimension \\
\hline
\end{tabular}

* Chemo = chemotherapy; Dx = diagnosis; $\mathrm{pts}=$ patients; recur = recurrence; $\mathrm{RT}$ = radiation therapy; $\mathrm{Tx}=$ treatment.

cluded a change in treated and untreated tumor volumes, overall and progression-free survival, and any change in KPS score within 14 days of treatment.

Treated patients were followed for a minimum of 6 months or until death, whichever occurred first. Neurological examinations, adverse events, and MRI sequences were assessed at postprocedure Days 1, 2, 3, 7, 14, 28, 56, 84 , and 168. All data were analyzed using SPSS Statistics software (IBM, Inc.). Toxicity was graded 1-5 according to the Cancer Therapy Evaluation Program's Common Terminology Criteria for Adverse Events (National Cancer Institute: Common Terminology Criteria for Adverse Events v3.0 [CTCAE]. Bethesda, MD, National Cancer Institute, 2006. [http://ctep.cancer.gov/forms/ ctcaev3.pdf]). These are precisely defined by the Cancer Therapy Evaluation Program for various criteria, but in general the following simplification is usually accurate: Grade 1, mild; Grade 2, moderate; Grade 3, severe; Grade 4, life threatening; and Grade 5, death.

Patient accrual began in September 2008 and ended in October 2009.

\section{The NeuroBlate System}

An overview of the equipment and equipment layout is shown in Fig. 2. The laser probe is $3.3 \mathrm{~mm}$ in diameter and is internally cooled using $\mathrm{CO}_{2}$ gas. The laser energy $(1064 \mathrm{~nm})$ exits the probe almost perpendicularly (side- firing probe) through a sapphire tip (Fig. 2, inset D). The laser source is a $12-\mathrm{W}$ pulse mode diode laser $(1064 \mathrm{~nm}$, cycle of 1.6 seconds in on mode and 2.2 seconds in off mode).

The NeuroBlate System monitors and visually reports the temperature of tissue and the thermal dose-the biological effect function of time and tissue temperature initially described by Sapareto and Dewey. ${ }^{20}$ By convention the temperature commonly used in reporting experimental thermal dosage equivalence is $43^{\circ} \mathrm{C}$. Tissues exposed to temperatures of $43^{\circ} \mathrm{C}$ or higher for $\geq 60 \mathrm{~min}$ utes initiate apoptosis and die within 48 hours. Tissues exposed to $43^{\circ} \mathrm{C}$ for shorter periods of time have a decreased level of damage, which has been refined empirically through preclinical testing and canine and porcine models (unpublished data, Monteris Medical, Inc.). The NeuroBlate software determines the likelihood of eventual cell death across the monitored tissue following laser thermal therapy.

For this study, the software demarcated 3 different thermal dose volumes ("yellow," "blue," and "white") in the monitored tissue (Table 2, Fig. 3). The white region defined tissue exposed to the thermal equivalent of $43^{\circ} \mathrm{C}$ for 60 minutes. Preclinical studies indicated that all tissue within this boundary died in $\leq 48$ hours. The yellow region represented tissue that had been exposed to the thermal equivalent of $43^{\circ} \mathrm{C}$ for 2 minutes. Preclinical 


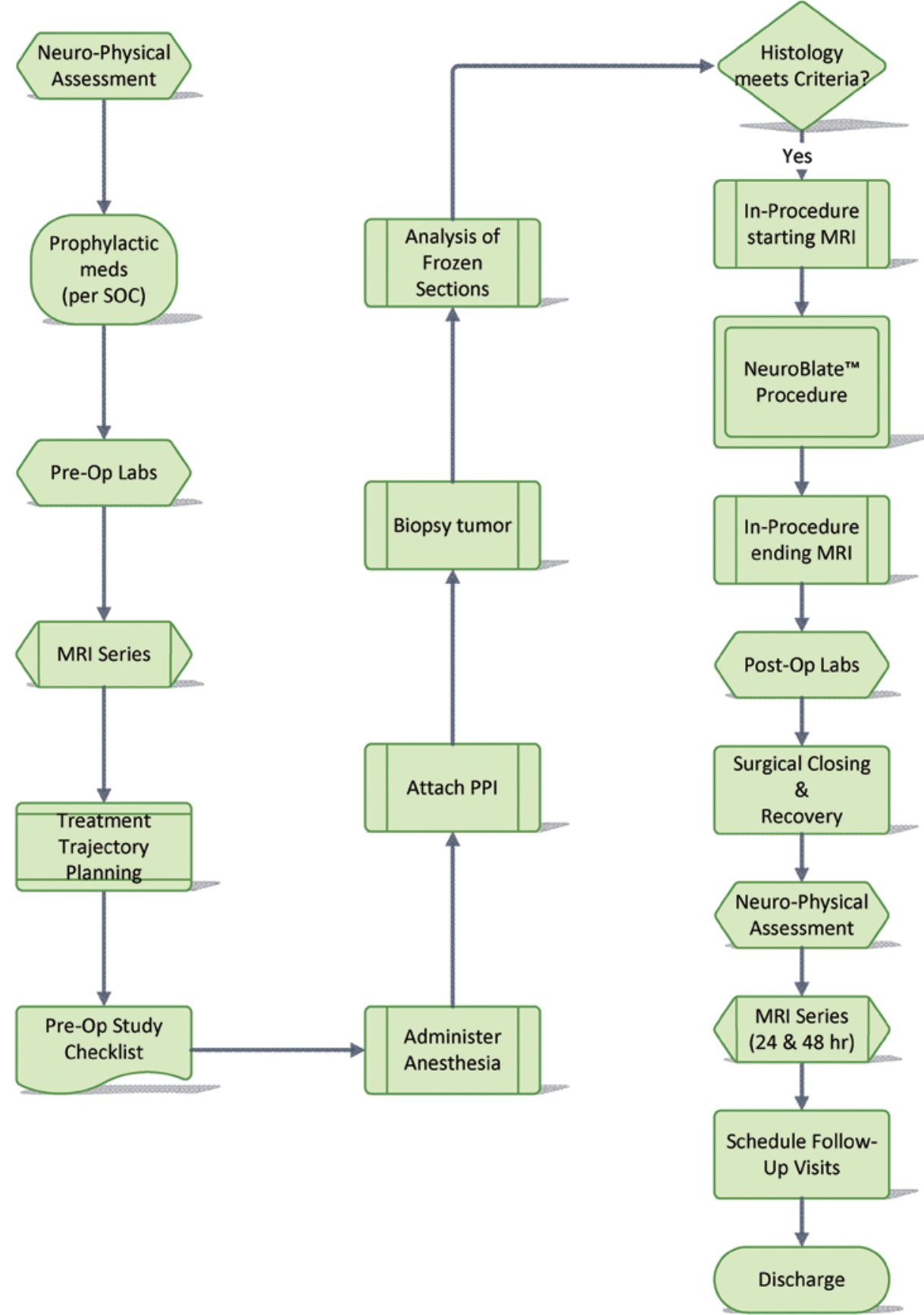

FIG. 1. Chart showing the workflow of the NeuroBlate first-in-humans study for rGBM. PPI = probe-patient interface; SOC = standard of care.

studies demonstrated that tissue outside of this yellow boundary line suffered no irreversible damage. The blue region defined tissue exposed to the thermal equivalent of $43^{\circ} \mathrm{C}$ for 10 minutes. This time period was selected based on empirical data suggesting that the degree of tissue damage after exposure to $43^{\circ} \mathrm{C}$ for 10 minutes was midway between that at exposures of 2 and 60 minutes. Tissue around this line may or may not undergo fatal thermal changes depending on a multitude of physiological factors. The MRI thermometry monitoring used a fast radiofrequency-spoiled gradient recalled echo sequence
(FOV $25.6 \times 25.6 \mathrm{~cm}$; matrix $128 \times 128$; TE $19.1 \mathrm{msec}$; TR $81 \mathrm{msec}$; flip angle $30^{\circ}$; bandwidth $100 \mathrm{~Hz} /$ pixel; and 3 slices of $5-\mathrm{mm}$ thickness). This sequence required approximately 7.8 seconds for a single acquisition, and multiple acquisitions were obtained continuously during every laser firing.

\section{Surgical Technique}

The workflow as performed in the trial is shown in Fig. 1. Preoperative contrast-enhanced T1-weighted volu- 
TABLE 2: Definition of thermal damage threshold dosages*

\begin{tabular}{lll}
\hline Line Color & TD Level & TD Equivalent \\
\hline yellow & $\mathrm{TD}_{\text {low }}$ & 2 min at $43^{\circ} \mathrm{C}$ \\
blue & $\mathrm{TD}_{\text {medium }}$ & 10 min at $43^{\circ} \mathrm{C}$ \\
white & $\mathrm{TD}_{\text {high }}$ & 60 min at $43^{\circ} \mathrm{C}$ \\
\hline
\end{tabular}

* $\mathrm{TD}=$ thermal dose.

metric images (isotropic 1-mm voxels-magnetizationprepared rapid acquisition gradient echo) were transferred to iPlan version 2.3 (Brainlab), and the probe trajectory and skull entry point were planned. In general trajectory planning was similar to that used for biopsy, except that an attempt was made to select a trajectory along the center of the long axis of the lesion to optimize NeuroBlate treatment. In some cases DTI-FT was also used during planning to identify nearby critical white matter tracts.

In the operating room, after induction of general anesthesia, a Mayfield 3-point fixation apparatus was attached to the patient's head and a trajectory guidance device (Navigus; Medtronic, Inc.) was secured to the skull. The Navigus had been previously modified to allow for securing the laser probe control mechanism. The patient underwent a brain biopsy directed by a Brainlab VectorVision surgical navigation system. Before proceeding with NeuroBlate treatment, confirmation of viable tumor was verified by histological analysis of frozen sections performed by a fellowship-trained neuropathologist.

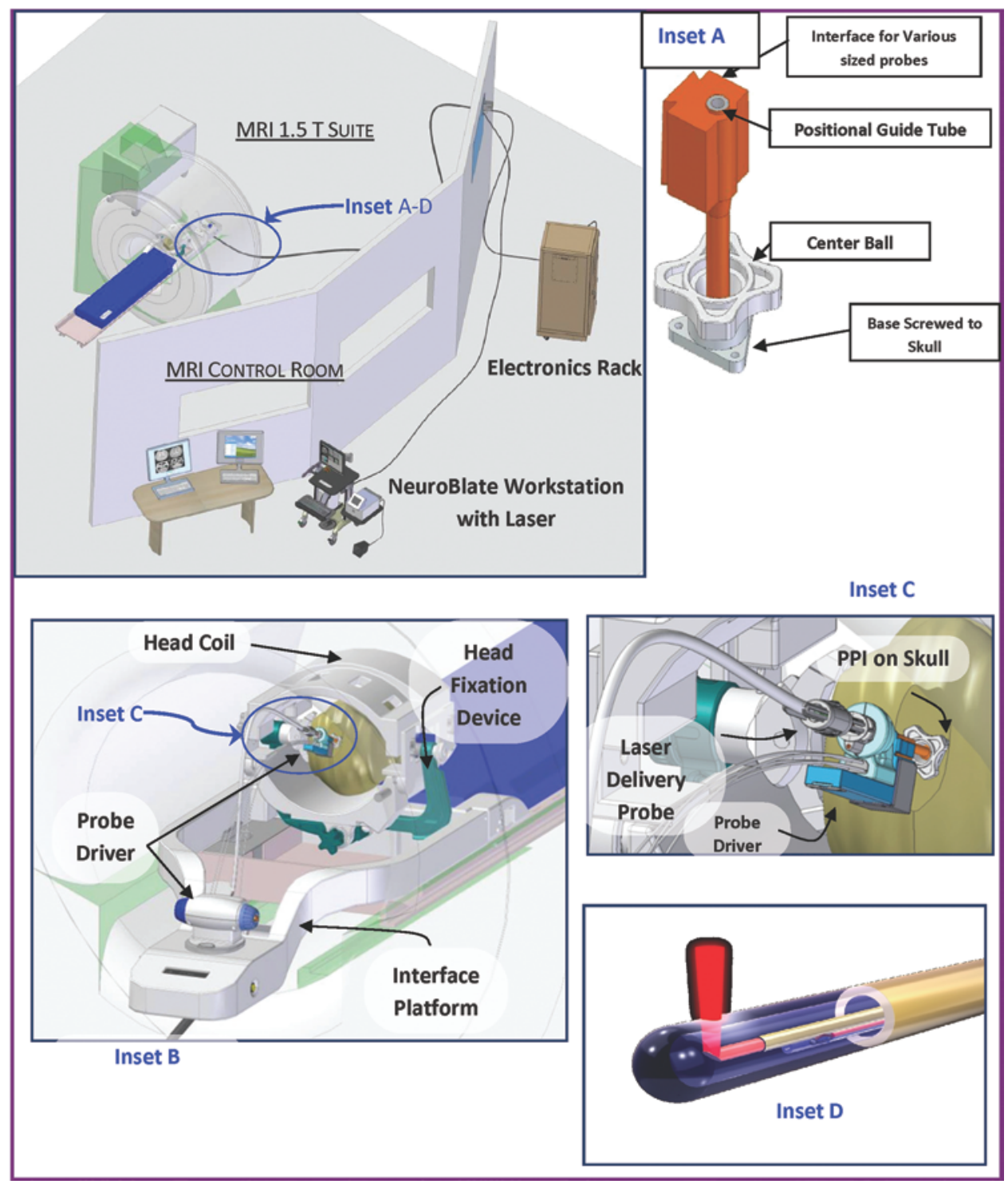

FIG. 2. Schematics showing layout of MRI suite adapted for the NeuroBlate procedure. The NeuroBlate electronics rack and workstation are situated in the MRI control room adjacent to the imaging suite. The cooling line, fiberoptic cable, and temperature probe cable are passed into the imaging suite through a wave guide. Inset A: Modified Navigus device. Inset B: Intraoperative MRI interface platform and probe driver. Inset C: Close-up of probe driver. Inset D: Tip of laser probe showing laser beam emerging out of the sapphire capsule. 

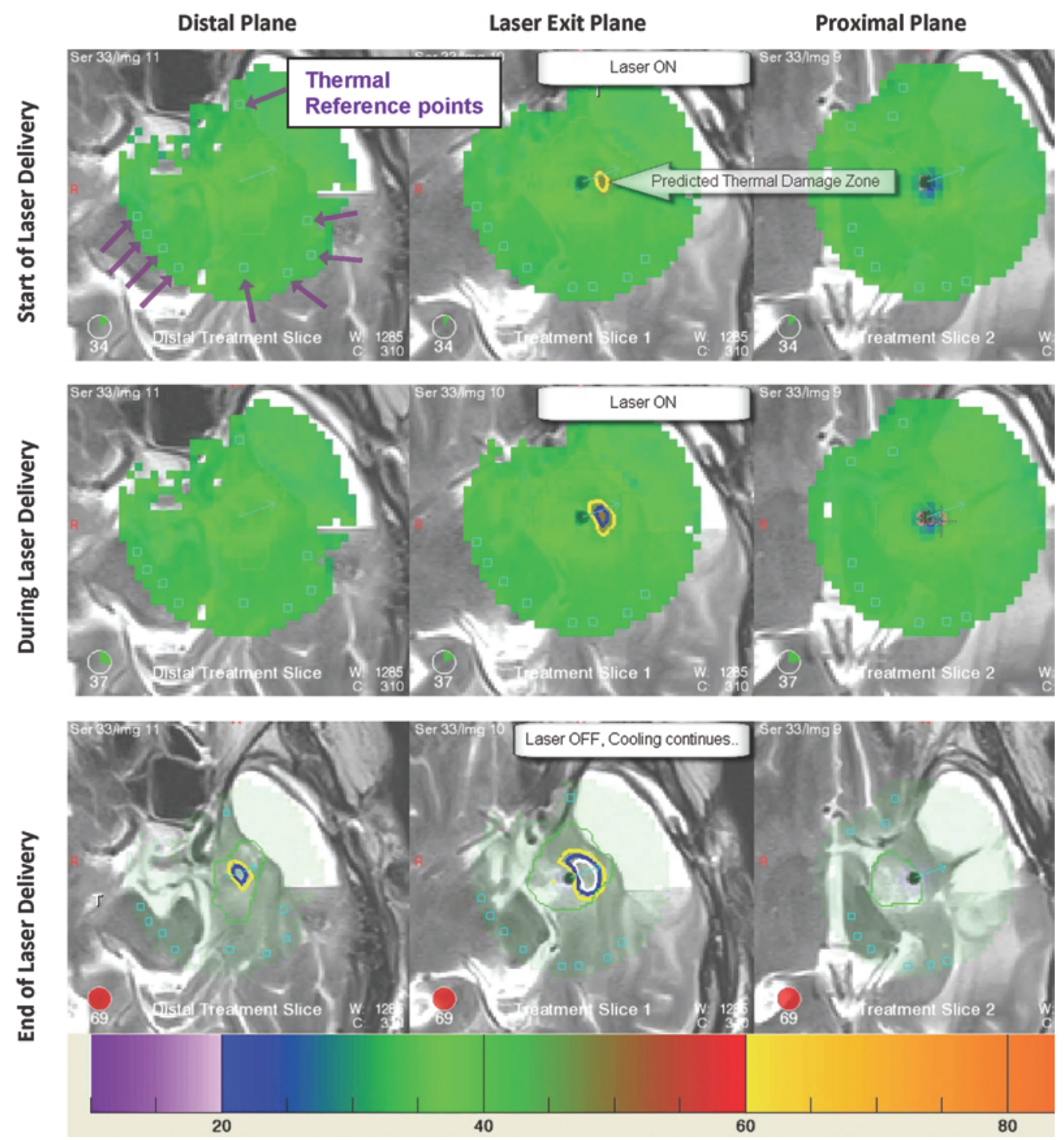

FIG. 3. NeuroBlate software generated predictive thermal dosage lines (damage threshold) used in this study; yellow (lowest dose), blue (intermediate dose), and white (highest dose). Illustrative time course of MRI thermometry presented by NeuroBlate software. Region of thermometry monitoring (green area; not shown in row 3), temperature reference points (small light blue squares, identified by violet arrows in the first panel), and thermal dosage lines (yellow and blue). The 3 panels in each row represent 3 successive "slices" perpendicular to the probe axis: the left panel is the most distal (nearest to the end of the sapphire capsule of the probe); the center panel is at the plane of laser exit from the probe; and the right panel is the slice proximal to the laser exit. A temperature (in ${ }^{\circ} \mathrm{C}$ ) color key is shown at the bottom.

After biopsy, the Navigus device (Fig. 2, inset A) was left in place, additional sterile draping was applied, and the patient was transported, under anesthesia, to the MRI suite (1.5-T imager, Siemens AG) for NeuroBlate treatment. The laser probe fiberoptic cable, cooling system, and other lines passed through a wave guide into the control room to the NeuroBlate control system (Fig. 2). The MRI apparatus was then appropriately draped and the probe driver was securely affixed to the Navigus (Fig. 2 , insets $\mathrm{B}$ and $\mathrm{C}$ ). The probe driver gives the surgeon remote control of probe rotation and translation.

Pretreatment MR images included FLAIR, T2* diffusion-weighted, and T1-weighted volume spoiled gradient-recalled acquisition in the steady state. T1-weighted spin echo images that included an image volume containing the probe trajectory were acquired for NeuroBlate treatment target planning. Using the NeuroBlate software and the T1-weighted images, the surgeon then manually segmented the tumor. The surgeon also identified temperature reference points outside the tumor but within $2 \mathrm{~cm}$ of the tumor margin (Fig. 3). Confirmation of the trajectory set on the Navigus in the operating room was verified and, if necessary, adjusted by repositioning the Navigus and performing confirmatory imaging. The laser probe was introduced manually to within $40 \mathrm{~mm}$ of the final target point, then advanced to the target by using the probe driver.

During treatment, real-time thermometry data were 
displayed by the software in 3 consecutive images $(5-\mathrm{mm}$ thick and $0.25-\mathrm{mm}$ gap) in a plane perpendicular to the probe (Fig. 3). As illustrated in the upper row of MR images, as the laser is engaged, thermal deposition is typically first observed in the treatment "slice"-the plane containing the location of the laser exit (center row of images). The lowest thermal dose demarcation appears first and begins to enlarge with continued lasing (center and lower rows of images).

Each patient was assigned to a single dose level, and the surgeon attempted to optimize the delivery of the assigned dose to the tumor volume while minimizing dose to surrounding nonneoplastic tissue. Deposition of thermal energy outside the tumor into cisterns, ventricles, sulci, and subarachnoid space was permitted at the discretion of the surgeon. Depending on the size and geometry of the tumor, applications of laser energy at multiple angles and depths were required.

Laser treatment was initiated by the surgeon and stopped manually when it was thought that the predicted thermal ablation zone was sufficient or automatically if any monitored limits were exceeded. Typically, laser treatment occurred in an iterative process within a treatment plane until the thermal dose volume conformed to the tumor boundary. As additional laser applications were performed, previously calculated thermal doses were added to subsequent overlapping laser applications. The probe was either advanced or retracted to treat other planes within the tumor until maximum coverage of the prescribed thermal injury was achieved.

\section{Timing of Subsequent Treatment Modalities}

Following the 14th day after NeuroBlate treatment, the patient was eligible to engage in other treatment modalities (for example, chemotherapy). These additional treatments and any impacts were reported only as clinical observations (Appendix table).

\section{Data and Calculations}

Patient demographic data, the location of the tumor, and clinical data were compiled according to standard clinical criteria. The "eloquence" of the tumor was graded I-III by using the criteria of Sawaya et al. ${ }^{21}$ (Table 3). The amount of edema on the 48-hour postoperative MRI was graded qualitatively with a score of 0 (no detectable edema), 1 (moderate edema without significant shift), or
2 (severe regional edema with mass effect or shift). The largest tumor dimension (D1) was defined as the widest dimension of the tumor in a plane perpendicular to the axis of the trajectory. The secondary dimension (D2) was defined as the widest dimension of the tumor perpendicular to both D1 and the axis of the trajectory (Fig. 4).

Before treatment, an initial tumor volume margin was defined by the surgeon and enclosed the intended target tissue $\left(\mathrm{V}_{\mathrm{T}}\right)$. Subsequent to treatment, the treated volume $\left(V_{D}\right)$ was identified. These 2 volumes help to define 3 distinct, nonoverlapping regions (Fig. 5): 1) an undosed volume $\left(\mathrm{V}_{\mathrm{U}}\right)$ - the portion of the $\mathrm{V}_{\mathrm{T}}$ that did not overlap with the $\left.\mathrm{V}_{\mathrm{D}} ; 2\right)$ a volume $\left(\mathrm{V}_{\mathrm{I}}\right)$ - where $\mathrm{V}_{\mathrm{T}}$ and $\mathrm{V}_{\mathrm{D}}$ overlap; and 3) a volume $\left(\mathrm{V}_{\mathrm{A}}\right)$ - the portion of $\mathrm{V}_{\mathrm{D}}$ that did not overlap with $\mathrm{V}_{\mathrm{T}}$.

The PTT was calculated as $\mathrm{V}_{\mathrm{I}} / \mathrm{V}_{\mathrm{T}} \times 100$ according to the intended dose for each treatment. The conformality index was calculated as $\left(\mathrm{V}_{\mathrm{A}}+\mathrm{V}_{\mathrm{I}}\right) / \mathrm{V}_{\mathrm{I}}$. The total energy, laser pulses, and lasing time were recorded automatically by the NeuroBlate software.

\section{Results}

\section{Patient Demographic Data and History}

Ten patients were treated between September 2008 and October 2009, and the median follow-up was 8 months. Demographic data for the patients in this study are given in Tables 4 and 5 . The mean age was 55 years; 8 patients were male and 2 were female. The median preoperative KPS score was 80 (range 70-90). Tumors were located in various locations and relative to eloquent cortex, and were believed to be inoperable or "high risk" for open resection. Six tumors were on the left (dominant) side. Two tumors were in noneloquent cortex (Grade I), 5 were near eloquent cortex (Grade II), and 3 were located in eloquent regions of the brain (Grade III). The mean tumor dimensions were $28 \pm 5 \mathrm{~mm}$ for D1 (range 22-36 $\mathrm{mm}$ ) and $22 \pm 6 \mathrm{~mm}$ for D2 (range 12-34 mm). The mean volume of the MR enhancing aspects of the tumor was $6.8 \pm 5 \mathrm{~cm}^{3}$ (range $2.6-19 \mathrm{~cm}^{3}$ ). There was no statistical difference between the eloquence, D1, D2, or volume of the tumors treated at each of the 3 thermal dosages (Table 4). At the time of the procedure, the median time since diagnosis was 457 days (range 111-1726 days, mean 617.5 [SD 480.3] days; see Table 5). In addition, 1 patient was initially registered for the trial, but it was subsequently

TABLE 3: Classification of tumor eloquence*

\begin{tabular}{lll}
\hline \multicolumn{1}{c}{ Grade I: Noneloquent } & Grade II: Near Eloquent & \multicolumn{1}{c}{ Grade III: Eloquent } \\
\hline frontal or temporal polar region & near motor or sensory cortex & primary motor or sensory cortex \\
rt parietooccipital lesions & near calcarine fissure & visual center \\
cerebellar hemisphere lesions & near speech center & speech center \\
& corpus callosum & internal capsule \\
& near dentate gyrus & basal ganglia \\
& & hypothalamus/thalamus \\
& & brainstem \\
\hline
\end{tabular}

\footnotetext{
* Reprinted with permission from Sawaya et al: Neurosurgical outcomes in a modern series of 400 craniotomies for treatment of parenchymal tumors. Neurosurgery 42:1044-1056, 1998.
} 


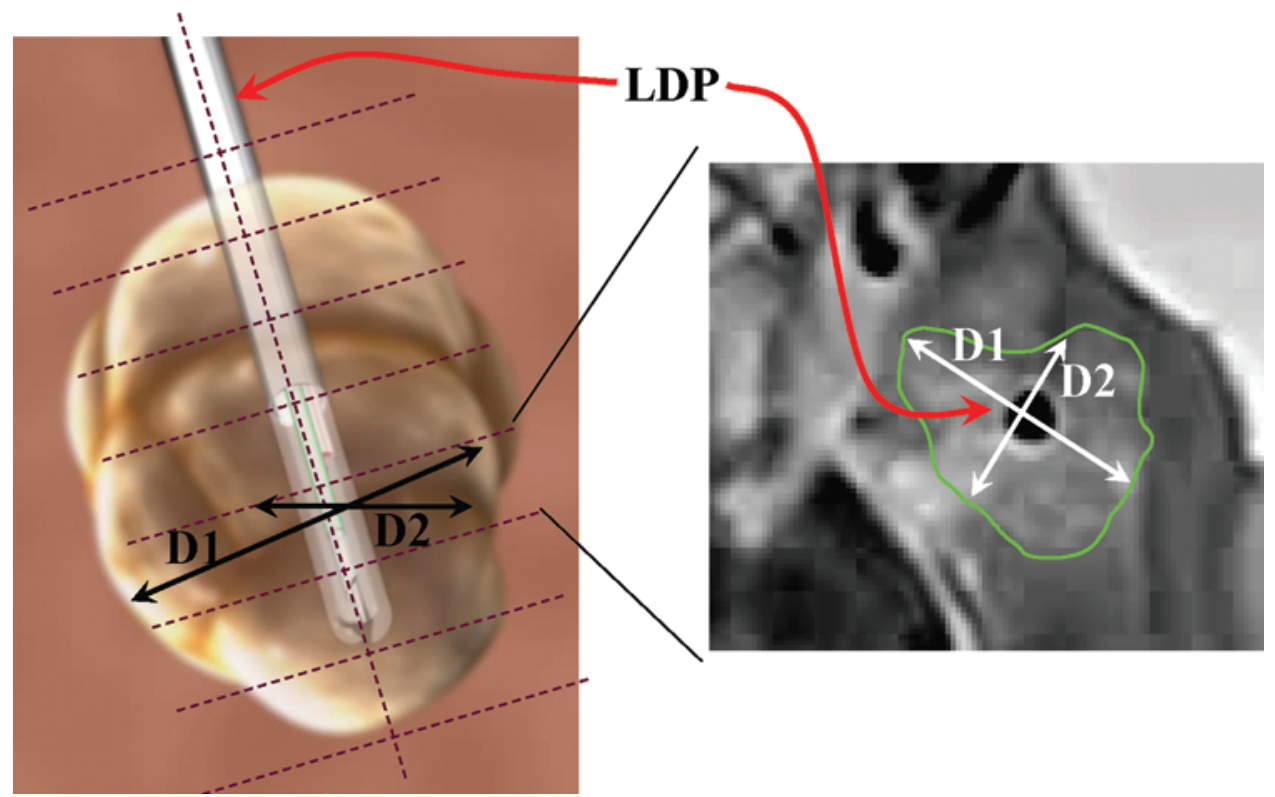

FIG. 4. Illustration demonstrating measurable parameters used to define treatment. Left: Volumetric representation of tumor. Right: Cross-sectional view. LDP = laser delivery probe.

determined that the depth of the tumor from the scalp was $106 \mathrm{~mm}$. Because the longest probe available for the trial was $105 \mathrm{~mm}$, the probe could not be positioned into the tumor, and treatment was not performed.

\section{Delivery of Thermal Dose}

The mean volume of tumor treated at the intended dose was $5 \pm 3.2 \mathrm{~cm}^{3}$ (range $1.98-11.03 \mathrm{~cm}^{3}$ ). The mean PTT at the intended dose level was $78 \%$ (range $57 \%-$ $90 \%$ ), and the mean modified conformality index was $1.21 \pm 0.33$ (range 1-2.04). There were no significant dif- ferences in $\mathrm{V}_{\mathrm{D}}, \mathrm{V}_{\mathrm{T}}$, PTT, or modified conformality index at the 3 thermal dose levels (Table 6).

In all cases, contrast-enhanced T1-weighted MRI studies performed at 24 and 48 hours after treatment showed necrosis at the treatment site. The NeuroBlate software accurately predicted the regions of treatment necrosis within the blue and white treatment zones; typically, these 2 regions were nearly concordant (Fig. 6).

Laser application times were 2-8 minutes per treatment slice. With prolonged lasing, the thermal energy spread beyond the treatment slice to the more distal moni-
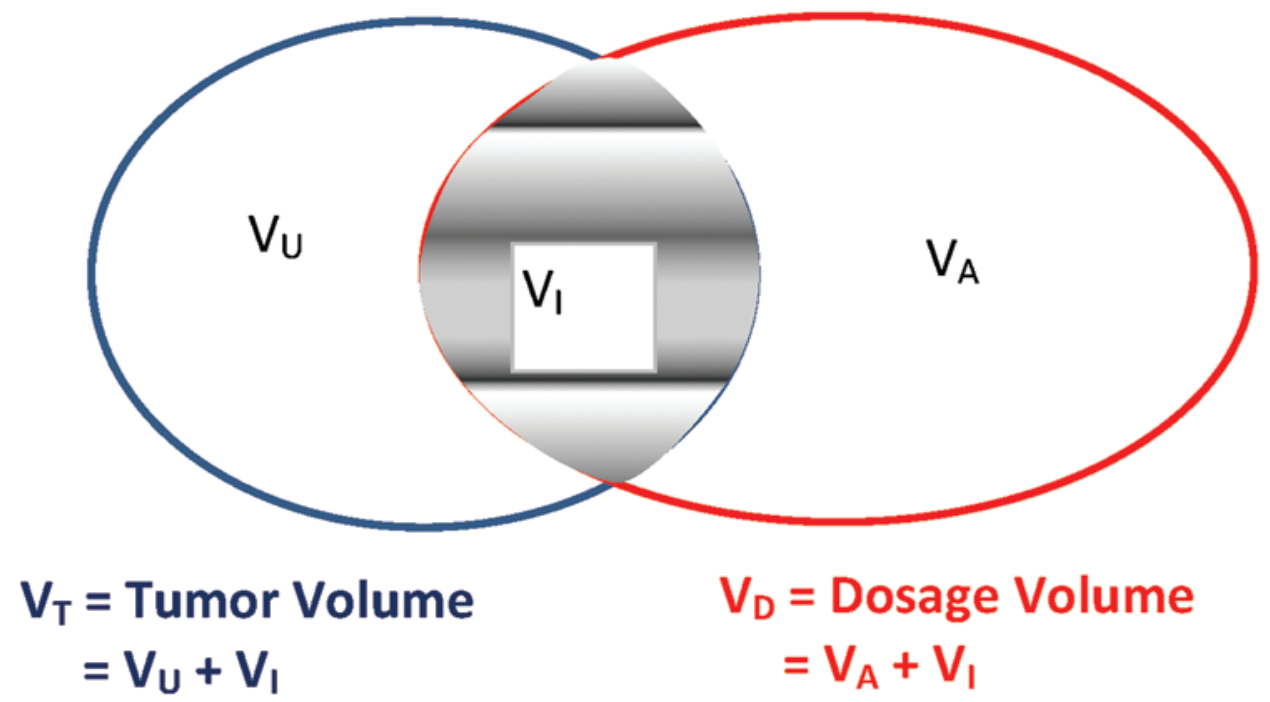

$$
\begin{aligned}
V_{D} & =\text { Dosage Volume } \\
& =V_{A}+V_{1}
\end{aligned}
$$

FIG. 5. Schematic showing surgeon-defined initial tumor margin enclosing the target tissue intended to be treated (labeled $V_{T}$ ). Following lasing, the delivered thermal dosage is designated as $V_{D}$. These regions define 3 distinct, nonoverlapping areas: an undosed region $\left(V_{U}\right)$, which is the portion of the $V_{T}$ that does not overlap with the $V_{D}$; $V_{1}$, where $V_{T}$ and $V_{D}$ overlap; and $V_{A}$, which is the portion of $V_{D}$ that does not overlap with $V_{T}$. 
TABLE 4: Characteristics in 10 patients with rGBMs at start of study

\begin{tabular}{ccccccccccc}
\hline $\begin{array}{c}\text { Case } \\
\text { No. }\end{array}$ & Tx Date & $\begin{array}{c}\text { Target Dosage } \\
\text { Threshold }\end{array}$ & $\begin{array}{c}\text { Age }(\mathrm{yrs}), \\
\text { Sex }\end{array}$ & Side & Location & Eloquence* & $\begin{array}{c}\text { D1 } \\
(\mathrm{mm})\end{array}$ & $\begin{array}{c}\text { D2 } \\
(\mathrm{mm})\end{array}$ & $\begin{array}{c}\text { Vol of Lesion } \\
\left(\mathrm{cm}^{3}\right)\end{array}$ & $\begin{array}{c}\text { Preop } \\
\text { KPS }\end{array}$ \\
\hline 1 & $9 / 24 / 08$ & yellow & $47, \mathrm{M}$ & It & temporal & III & 24 & 20 & 5.14 & 90 \\
2 & $12 / 30 / 08$ & yellow & $55, \mathrm{M}$ & It & temporoparietal & III & 36 & 34 & 19.01 & 70 \\
3 & $1 / 6 / 09$ & yellow & $66, \mathrm{~F}$ & rt & parietal & I & 28 & 27 & 9.88 & 80 \\
4 & $1 / 27 / 09$ & blue & $51, \mathrm{~F}$ & It & temporooccipital & II & 29 & 27 & 6.40 & 80 \\
5 & $3 / 12 / 09$ & blue & $55, \mathrm{M}$ & rt & temporal & II & 36 & 20 & 7.20 & 80 \\
6 & $4 / 3 / 09$ & white & $69, \mathrm{M}$ & rt & parietal & I & 31 & 12 & 2.60 & 70 \\
7 & $4 / 7 / 09$ & white & $63, \mathrm{M}$ & It & frontal & II & 22 & 15 & 2.63 & 90 \\
8 & $4 / 23 / 09$ & white & $44, \mathrm{M}$ & It & parietal & II & 27 & 25 & 12.81 & 90 \\
9 & $5 / 28 / 09$ & white & $55, \mathrm{M}$ & rt & frontal & III & 24 & 23 & 6.24 & 90 \\
10 & $10 / 7 / 09$ & white & $34, \mathrm{M}$ & It & frontal & II & 26 & 22 & 9.96 & 90 \\
\hline
\end{tabular}

* According to the scale proposed by Sawaya et al.

tored slice. Rarely was a significant thermal dose deposition seen in the more proximal monitored slice.

Dose deposition typically occurred in a controlled and predictable fashion. As illustrated in Fig. 7 upper, the surgeon selected the desired orientation of the laser (indicated by the light blue arrow at approximately the 11 o'clock position). After the appropriate thermal dose (yellow, in this case) reached the tumor margin (green area), lasing was stopped. In Fig. 7 lower, the probe has been rotated to approximately the 5 o'clock position at the same depth, and lasing resumed and was concordant with probe direction. When the surgeon stops lasing, the treatment zones stop enlarging within approximately 16 seconds (or approximately 2 MR thermometry images).

The surgeon was always able to observe laser deposition in real time. Occasionally the pattern of thermal deposition was counterintuitive. Figure 8 upper illustrates the treatment of the patient in Case 9. The laser was firing at approximately the 8 o'clock position (labeled treatment slice 4) with predicted thermal deposition orientation in both the treatment slice and the more distal slice (treatment slice 3). However, thermal deposition was also observed in the proximal slice (treatment slice 5) at approximately the 11 o'clock orientation and outside the region of the tumor segmentation. It was also observed that following lasing in a particular region, it was increasingly difficult to "push" additional thermal ablation past the damaged region in subsequent attempts (not illustrated). Figure 8 lower illustrates another example from the treatment of the patient in Case 8. While lasing at approximately the 2 o'clock position, in an effort to push the white dosage line to the tumor boundary, dose deposition occurred at the 5 o'clock and 10 o'clock positions, perpendicular to the expected direction of the laser and in the plane proximal to the laser exit.

\section{Clinical Outcomes}

The clinical outcomes of patients in the trial are summarized in Table 7. Overall the NeuroBlate procedure was well tolerated. All 10 patients were alert and responsive within 1-2 hours postoperatively, and 9 of the
10 were ambulatory within 4-12 hours. Although most patients were clinically stable (that is, without any pain in the surgical area, nausea, or headache) and suitable for discharge within 48 hours after the procedure, the study protocol mandated an MRI study and neurological assessment at 48 hours. Preoperative health status and investigator desire to observe any posttreatment effects (including delayed brain edema) resulted in longer hospital stays for some participants, especially those enrolled earliest. These factors resulted in a median hospital stay of 3 days, and this did not vary significantly by treatment dose. No probe entry site or CNS infections were reported within 2 months of follow-up; one entry-site infection was reported at 147 days postprocedure and was not attributed to the procedure or to the NeuroBlate device.

Treatment-related edema was evident on MR images at 48 hours postoperatively in nearly all patients. Edema was effectively managed with steroids. At the lowest thermal dose (yellow), no changes in postoperative KPS scores were observed. In the intermediate-dose (blue) and high-dose (white) groups, 3 patients had improved KPS scores at postoperative Day 14; improvements ranged from 10 points ( 2 patients) to 20 points ( 1 patient).

\section{Direct Toxicity}

Two patients developed temporary neurological deficits several days after the procedure; one patient reported dysphasia with mild upper-limb weakness contralateral to

TABLE 5: Prior treatment history in 10 patients with rGBMs

\begin{tabular}{lcrr}
\hline \multicolumn{1}{c}{$\begin{array}{c}\text { Parameter } \\
\text { (days before NeuroBlate) }\end{array}$} & Mean (SD) & Minimum & Maximum \\
\hline days after initial Dx & $617.5(480.3)$ & 111 & 1726 \\
days after recur & $58.1(61.2)$ & 13 & 198 \\
days since prior op & $613.7(482.0)$ & 111 & 1726 \\
days prior RT & $538.8(496.8)$ & 44 & 1696 \\
no. rounds of prior chemo & $2.3(0.9)$ & 1 & 4 \\
days since most recent chemo & $210(249.0)$ & 4 & 572 \\
\hline
\end{tabular}


NeuroBlate System first-in-humans trial

TABLE 6: Treatment parameters in 10 patients with rGBMs*

\begin{tabular}{|c|c|c|c|c|c|c|c|c|c|c|}
\hline \multirow{2}{*}{$\begin{array}{l}\text { Case } \\
\text { No. }\end{array}$} & \multirow{2}{*}{$\begin{array}{l}\text { Dose } \\
\text { Level }\end{array}$} & \multirow{2}{*}{$\begin{array}{c}\text { Total } \\
\text { Pulses }\end{array}$} & \multirow{2}{*}{$\begin{array}{l}\text { Total Lasing } \\
\text { Time (min) }\end{array}$} & \multirow{2}{*}{$\begin{array}{c}\text { Total } \\
\text { Energy }(\mathrm{J})\end{array}$} & \multicolumn{4}{|c|}{ Volume $\left(\mathrm{cm}^{3}\right)$} & \multirow{2}{*}{$\begin{array}{c}\text { PTT at } \\
\text { Intended Dose }\end{array}$} & \multirow[b]{2}{*}{ Conf Index $\left(\left[\mathrm{V}_{\mathrm{A}}+\mathrm{V}_{1}\right] / \mathrm{V}_{\mathrm{l}}\right)$} \\
\hline & & & & & $V_{1}$ & $V_{u}$ & $V_{A}$ & $\mathrm{~V}_{\mathrm{T}}$ & & \\
\hline 1 & yellow & 336 & 9.0 & 6,410 & 2.93 & 2.21 & 0.00 & 5.14 & 57 & 1.00 \\
\hline 2 & yellow & 630 & 16.8 & 11,940 & 11.03 & 7.98 & 0.00 & 19.01 & 58 & 1.00 \\
\hline 3 & blue & 280 & 7.5 & 5,297 & 7.90 & 1.98 & 5.35 & 9.88 & 87 & 1.68 \\
\hline 4 & blue & 1021 & 27.2 & 19,520 & 4.86 & 1.54 & 1.35 & 6.40 & 80 & 1.28 \\
\hline 5 & white & 645 & 17.2 & 12,310 & 5.11 & 2.09 & 1.25 & 7.20 & 75 & 1.24 \\
\hline 6 & white & 639 & 17.0 & 12,170 & 1.98 & 0.62 & 0.70 & 2.60 & 81 & 1.35 \\
\hline 7 & white & 1884 & 50.2 & 36,040 & 2.13 & 0.50 & 2.22 & 2.63 & 90 & 2.04 \\
\hline 8 & white & 933 & 27.4 & 19,410 & 10.63 & 2.18 & 1.38 & 12.81 & 85 & 1.13 \\
\hline 9 & white & 416 & 10.5 & 7,971 & 4.56 & 1.68 & 0.59 & 6.24 & 75 & 1.13 \\
\hline 10 & white & 1304 & 35.8 & 26,190 & 6.27 & 3.69 & 1.10 & 9.96 & 67 & 1.18 \\
\hline mean & & 642 & 17.1 & 12,240 & 4.99 & 2.04 & 1.18 & 6.80 & 78 & 1.21 \\
\hline$S D$ & & 495 & 13.5 & 9,687 & 3.24 & 2.14 & 1.54 & 4.99 & 12 & 0.33 \\
\hline
\end{tabular}

* Conf = conformality; $V_{A}=$ volume of nontumor treated at intended dose; $V_{1}=$ volume of initially defined tumor treated at intended dose; $V_{T}=$ volume of initially defined tumor; $V_{u}=$ volume of initially defined tumor outside intended dosage line.

the procedure, and another patient had mild contralateral weakness and homonymous hemianopia. Both deficits resolved after therapy with steroids.

Two patients suffered neurological deterioration due to the NeuroBlate procedure. The patient in Case 8 experienced a small intracerebral hemorrhage (arterial pseudoaneurysm) 6 weeks posttreatment. This was successfully treated by coil placement, and the patient did not suffer from any long-term neurological deficit. The patient in Case 9 suffered a white matter tract injury at the treatment site and experienced severe hemiparesis but eventually improved, regaining significant function in 6-8 weeks. This patient had not undergone preoperative DTIFT (which was not required by the protocol); however, no patient undergoing preoperative DTI-FT suffered a direct white matter injury in this study.

All serious (Grades 3-5; severe, life threatening, death) adverse events observed in this study are shown in Table 8.

\section{Other Adverse Events}

Three patients developed DVT ( 2 severe and 1 moderate), and 1 patient each developed Grade 3 neutropenia and a Grade 4 PE. The treating physicians did not attribute the thromboembolic events to the device.

More than 9 months postprocedure, 1 patient developed an epicranial gliosarcoma on and in the skull at the probe entry site. This mass was removed surgically without complication. It is unclear whether this was attributable to the biopsy, laser probe, or both.

There was no correlation of any type of adverse event with the dosage level (either by ANOVA or direct examination of the raw data). Similarly, there was no correlation between dosage level and event severity. Two cases of hemiparesis were noted in patients whose tumors were in eloquent (Grade III) or near eloquent (Grade II) cortex, although only one of these was severe. In addition, the 2 serious complications (in Cases 8 and 9) were associated with patterns of dose deposition that were counterintuitive.

All nonserious (Grades 1-2; mild and moderate) adverse events observed in this study are shown in Table 9. The median survival in this selected group of 10 patients was 316 days (range 62-767 days; Table 7, Fig. 9). Although the small study size makes statistical significance questionable, there was a trend for increased survival in the patients treated with the higher (white) thermal dose, including those with complications (Fig. 9 upper). There were only 2 deaths during the 6-month window of the study's prescribed follow-up period; one in a patient treated at the yellow thermal dose and another in one treated at the blue dose. Both patients suffered progression of the underlying disease and were entered into hospice rather than receiving additional treatment. No deaths were related to the treatment procedure or device. At least 3 patients entered into subsequent clinical trials after completing the mandated 14-day observation point.

\section{Discussion}

\section{Technical Limitations and Characteristics}

The mean percentage of treated tumor at the intentto-treat dose in this trial was $78 \% \pm 12 \%$ (range $57 \%$ $90 \%$; Table 6). This is lower than other treatments using focused energy for tissue ablation and does not meet the goal of $98 \%$ resection, which correlated with improved survival in previous series of resected GBM. ${ }^{11}$ However, it should be recognized that this limitation was due in part to the trial design as mandated by the FDA, which allowed only a single probe trajectory to be used. Additional technical challenges were related to the limited trajectories achievable with available cranial immobilization devices and the design of available MRI coils, which limited trajectories to the vertex of the skull. Nonetheless, the favorable clinical outcomes observed (discussed below) suggest that despite these limitations, NeuroBlate may 
A. E. Sloan et al.

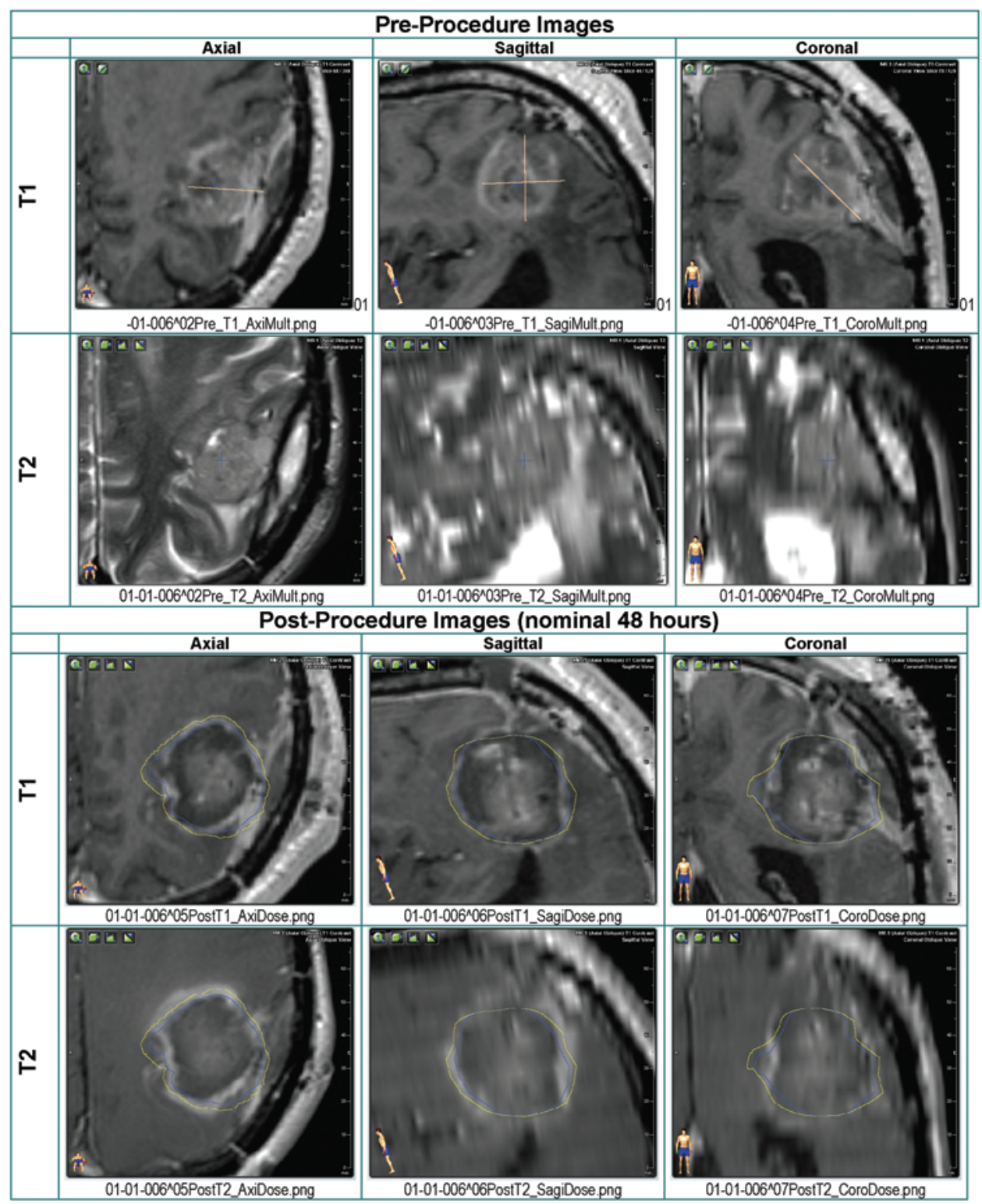

FIG. 6. Axial, sagittal, and coronal T1- and T2-weighted (as marked) MRI studies obtained before and 48 hours after a NeuroBlate procedure. Note that the yellow line in the postprocedural images is the extent of predicted ablation by the blue (medium) target dosage threshold, and that this conforms very well with the extent of observed laser ablation at 48 hours.

be clinically beneficial. This observation is also consistent with a recent study demonstrating that resection of as little as $78 \%$ of a GBM conferred a survival benefit. ${ }^{19}$ Furthermore, new technical innovations such as novel miniframes that permit increased trajectory angles as well as multiple trajectories using a single bur hole ( $\mathrm{S}$. Manjila, K. Knutson, A.E. Sloan, unpublished data) have recently become available. Novel MRI coil designs enabling improved access to the cranium from a variety of angles are currently under development. These should enable future surgeons to achieve greater coverage of tumor at the selected thermal dose.

Although resection of rGBM appears to be effective in up to one-third of patients, ${ }^{1}$ many are not candidates for resection of rGBM for a variety of reasons. Previous at- tempts in which less invasive approaches such as brachytherapy ${ }^{4,27}$ and stereotactic radiosurgery ${ }^{28,30}$ were used have proven ineffective in recent meta-analysis and randomized trials. However, unlike therapies using ionizing radiation, NeuroBlate therapy results in tumor death over a period of only a few days. In addition, the near realtime feedback of the thermal dose delivery enables the surgeon to precisely control the damage inflicted on the tumor.

A conformality index is a measure of the "precision" of the delivery of treatment energy to a tumor relative to the total volume of brain (tumor + nontumor) receiving this dose. In contrast to SRS, for which a conformality index of $\leq 2.0$ is generally considered well tolerated, ${ }^{26}$ conformality indices as low as 1.00 and 1.24 were associ- 

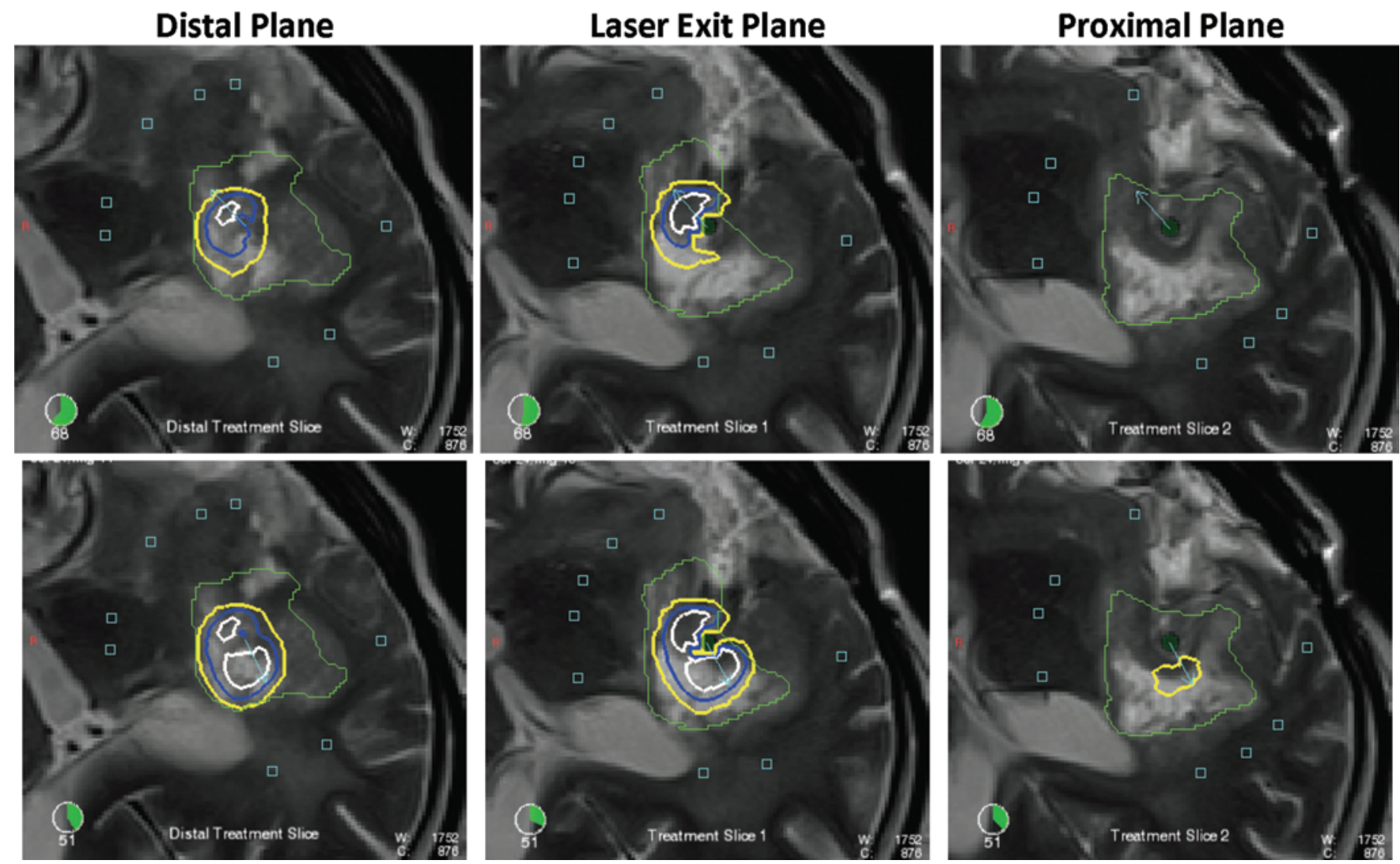

FIG. 7. Dose deposition was usually predictable. Illustration of thermal dose lines and directionality (blue arrows) of laser probe. Upper: Row of images showing the probe pointing to approximately 11 o'clock, with a corresponding deposition of thermal energy. Lower: Row of images showing the same coordination of energy deposition, with the probe firing at approximately 5 o'clock (including dosage from prior firings).

ated with transient mild motor and/or speech deficits in patients at the low and medium thermal doses, respectively, although both patients recovered fully after steroid treatment (Tables 6 and 7). In addition, treatments with a conformality index of 1.13 resulted in a ruptured pseudoaneurysm and significant damage to the primary motor tract, respectively, in 2 patients at the highest dose. Thus, whereas NeuroBlate is safe, the temporal dynamics and tissue damage induced by thermal ablation are clearly different from those associated with SRS, for which the MRI evidence of treatment effect often appears in 3-6 months rather than within 48 hours. Greater surgical precision and caution may be required for LITT than SRS. It should also be noted that both patients who sustained damage at the higher dose levels also had the probe adjacent to critical structures (vessels or eloquent fiber tracts). In addition, in both cases, dose deposition occurred in a counterintuitive fashion (Fig. 8). This suggests that perhaps a more careful preoperative imaging session including MR angiography and DTI-FT would probably help avoid damage. Indeed, although preoperative DTI-FT was not a requirement of the study, no patient in whom DTI-FT was used suffered a sustained tract injury. Also, because the surgeon can observe the thermal dose deposition in real time, damage may be preventable if the surgeon stops lasing when unexpected thermal deposition is observed because it suggests an unanticipated "heat sink" that may represent a vessel or a fiber tract. Improved understanding and prediction of tissue response to thermal therapy and additional metrics to describe this phenomenon are important topics for future study.

\section{Patient Outcomes}

The median time since diagnosis in this group of patients was 457 days (range 111-1726 days) at the time of the procedure. Hence this was a highly selected group of patients who had received a median of 2 previous therapies (range 1-4; see Appendix table). The median survival time seen in this small cohort of patients after NeuroBlate is encouraging at 316 days, as compared with the $90-$ to 150-day median survival typically observed for rGBM. ${ }^{1}$ The median progression-free survival at 6 months in rGBM is $15 \%,{ }^{1}$ and in this study it was estimated to be greater than $30 \%$ (the small study size only allows for a lower-limit estimate). The favorable survival results may be due in part to selection bias because the entry criteria required patients with unifocal tumors $1-4 \mathrm{~cm}$ in maximum diameter. The mean tumor size in this group was $27.5 \times 22.5 \mathrm{~mm}$ (range $22 \times 15 \mathrm{~mm}$ to $36 \times 34 \mathrm{~mm}$ ), and the mean volume was $6.8 \mathrm{~cm}^{3}$ (range $2.6-19 \mathrm{~cm}^{3}$ ). The prolonged survival in this heavily pretreated group suggests that NeuroBlate may be an appropriate treatment for 
Distal Plane
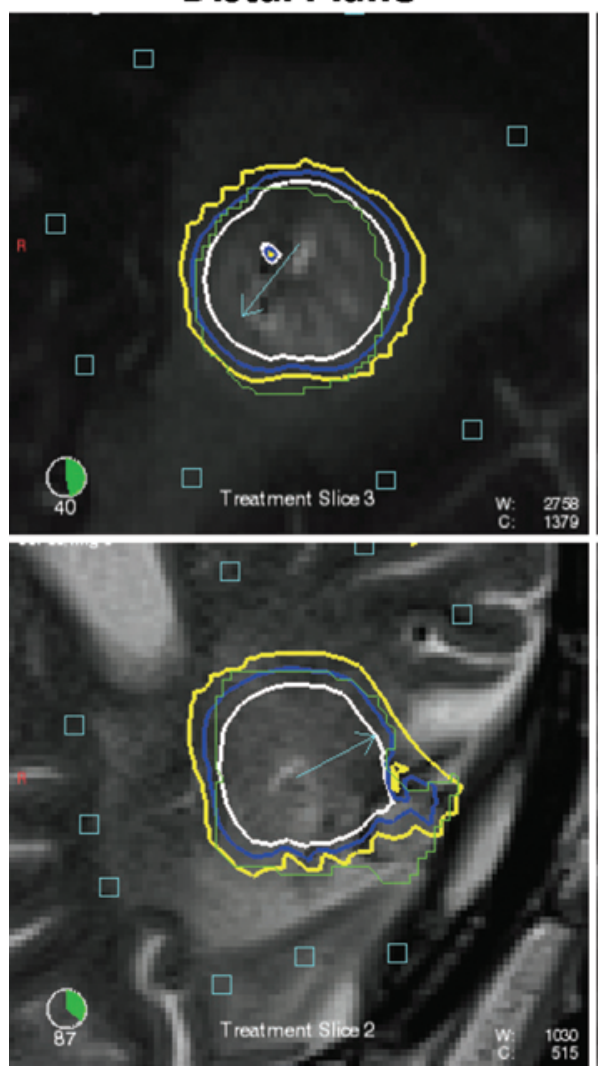

Laser Exit Plane
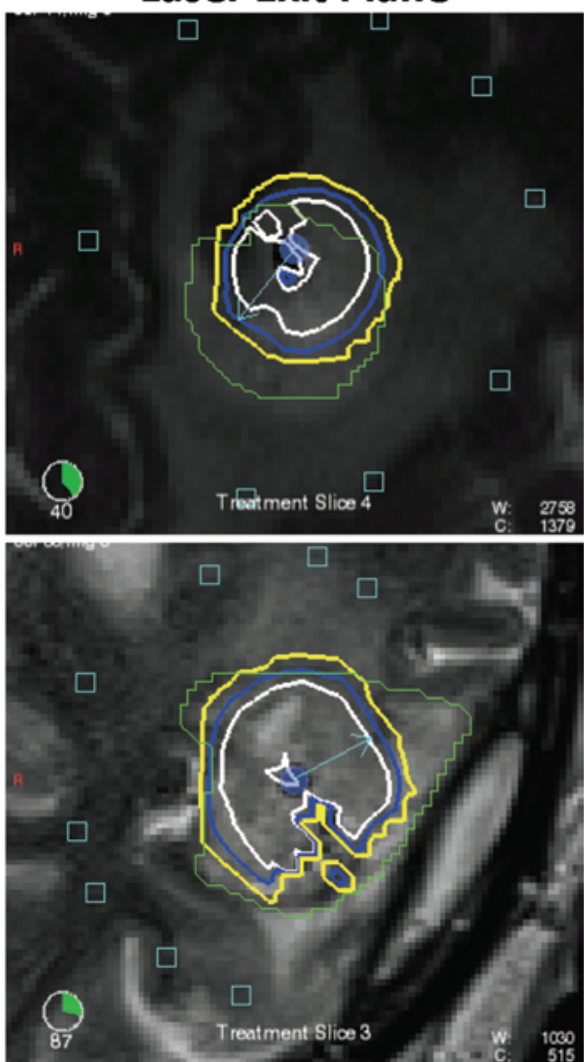

Proximal Plane

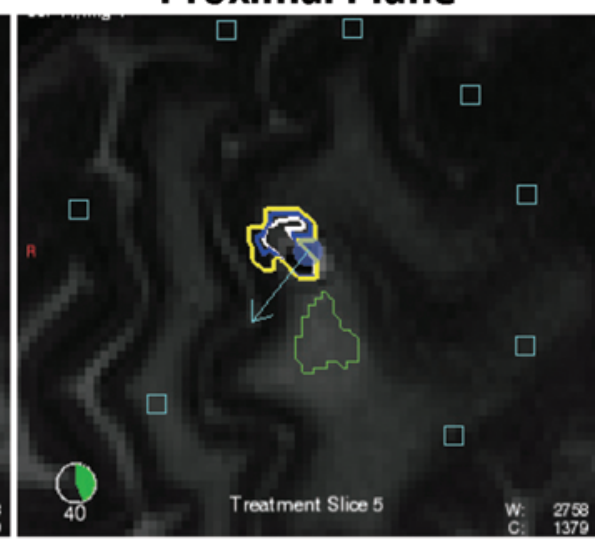

Fig. 8. Occasionally the pattern of thermal deposition was counterintuitive. Upper: Note that in the third treatment slice (image labeled treatment slice 5) the laser direction (blue arrows) is at 8 o'clock, whereas the thermal effect is seen at 11 o'clock and proximal to the plane of laser exit (laser exit is in plane with treatment slice 3). Lower: In the third treatment slice (image labeled treatment slice 4) the laser direction is set at 2 o'clock, whereas the thermal effect is seen at both 5 o'clock and 10 o'clock proximal to the plane of laser exit (treatment slice 3).

patients with rGBM. About one-third of this study cohort entered subsequent clinical trials, as is typical of this patient population. Furthermore, NeuroBlate can be easily combined with other treatment modalities because most patients can start additional therapies 2 weeks postprocedure, as in this trial. An intriguing possibility regarding this greater than expected survival is that the thermal effects of the NeuroBlate treatment extend beyond the region of coagulation, with a preferential toxic effect of hyperthermia on nearby tumor cells.

Overall, NeuroBlate was a well-tolerated treatment. The degree of postoperative edema was moderate and easily controlled with steroids. A possible explanation for this could be that procedure-generated edema was partially moderated by a reduction in the volume of surviving tumor cells. Nonetheless, 2 patients developed temporary neurological deficits several days after the procedure: one had dysphasia with arm weakness and the other had homonymous hemianopia. Both deficits were considered preoperative and resolved after therapy with steroids.

Two patients had serious neurological adverse events due to the NeuroBlate procedure, both at the highest dose level. The patient in Case 8 suffered a small intracerebral hemorrhage due to an arterial pseudoaneurysm 6 weeks after treatment. This was successfully managed by endo- vascular coil placement with no long-term neurological deficit. The vessel affected was in contact with the target tissue, and the damage to the vessel, in a retrospective review, was apparent on immediate postprocedural MRI studies. In the future, when there are vascular concerns near target tissues, pre- and posttreatment angiography (via CT and/or MRI modalities) may be considered to allow the surgeon to avoid thermal dosing of delicate vasculature and to assess the local vascular fidelity before a patient is discharged. The patient in Case 9 experienced severe hemiparesis on awakening from the procedure but eventually improved, regaining significant function in 6-8 weeks. This event was attributed to the proximity of a motor tract to the target tumor and to the fact that denser tissues like nerve bundles, pial surfaces, and vascular structures appear to absorb thermal energy better than normal parenchyma (unpublished preclinical observations).

In addition, the trial design specified that the maximal dose (white) be applied to the target tissue adjacent to this eloquent region. In the future, pretreatment fiber tract mapping using DT MRI should be incorporated into the procedure. This will facilitate appropriate caution and avoidance of thermal injury or application of a lower thermal dose (blue) to eloquent structures in the future. 
NeuroBlate System first-in-humans trial

TABLE 7: Clinical outcomes in 10 patients with rGBMs*

\begin{tabular}{|c|c|c|c|c|c|c|}
\hline $\begin{array}{l}\text { Dose Level \& } \\
\text { Case No. }\end{array}$ & $\begin{array}{c}\text { Days of Hospital } \\
\text { Stay }\end{array}$ & $\begin{array}{c}\text { Edema at } \\
48 \mathrm{Hrs} \dagger\end{array}$ & $\begin{array}{l}\text { Change in KPS } \\
\text { Score at Day } 14\end{array}$ & $\begin{array}{c}\text { Neurological } \\
\text { Complications at Day } 14\end{array}$ & $\begin{array}{c}\text { Neurological } \\
\text { Complications at } \\
\text { Day } 84\end{array}$ & $\begin{array}{l}\text { Days of Survival } \\
\text { Post-LITT }\end{array}$ \\
\hline \multicolumn{7}{|l|}{ yellow } \\
\hline 1 & $2(4.3)$ & $2+(3)$ & $0(0)$ & none & none & $314(225)$ \\
\hline 2 & 7 & 1 & 0 & mild dysphasia & none & 265 \\
\hline 3 & 4 & 0 & 0 & none & none & 96 \\
\hline \multicolumn{7}{|l|}{ blue } \\
\hline 4 & $3(3.5)$ & $1+(2)$ & $+10(5)$ & none & none & 334 (198) \\
\hline 5 & 4 & $2+$ & 0 & mild hemiparesis, $\mathrm{HH}$ & none & 62 \\
\hline \multicolumn{7}{|l|}{ white } \\
\hline 6 & $3(3.4)$ & $2+(1+)$ & $+20(0)$ & none & none & $485(434)$ \\
\hline 7 & 3 & $2+$ & 0 & none & none & 305 \\
\hline 8 & 3 & $1-2+$ & 0 & none & pseudoaneurysm & 319 \\
\hline 9 & 6 & $1+$ & -30 & severe hemiparesis & mod hemiparesis & 434 \\
\hline 10 & 2 & $1+$ & +10 & none & none & 767 \\
\hline overall median & 3 & & & & & 316 \\
\hline $\mathrm{Cl}$ & $2-7$ & & & & & 265 \\
\hline
\end{tabular}

* Values in parentheses are medians at the indicated dose. Abbreviations: $\mathrm{HH}=$ homonymous hemianopia; mod = moderate.

$\dagger$ Edema scores: 0 = no detectable edema; 1 = moderate edema without significant shift; 2 = severe regional edema with mass effect or shift.

Also of note, both patients who suffered serious adverse consequences were noted to have unexpected patterns of thermal energy deposition (Fig. 4). This suggests the need for careful observation of the patterns of thermal deposition during LITT and that such unexpected patterns require additional intraoperative scrutiny and caution. Additional study of such unexpected patterns may yield further insight and should be the topic of future study.
Although the maximum tolerated dose was not reached even at the highest dose used in the study, the observation that the 2 most serious adverse consequences were unpredictable suggests that keeping the current highest dose (white; $43^{\circ} \mathrm{C}$ for 60 minutes) in use until the effects of LITT are better understood and more predictable appears to be prudent.

One patient developed an epicranial gliosarcoma

TABLE 8: Serious adverse events seen in the study, by dose level*

\begin{tabular}{|c|c|c|c|c|c|c|c|c|c|c|c|c|}
\hline \multirow[b]{2}{*}{ Toxicity } & \multicolumn{4}{|c|}{ Yellow } & \multicolumn{4}{|c|}{ Blue } & \multicolumn{4}{|c|}{ White } \\
\hline & Severe & LT & Fatal & Subtotal & Severe & LT & Fatal & Subtotal & Severe & LT & Fatal & Subtotal \\
\hline neutropenia & 1 & & & 1 & & & & 0 & & & & 0 \\
\hline postop WI & & & & 0 & 1 & & & 1 & & & & 0 \\
\hline VPR & & & & 0 & & & & 0 & 1 & & & 1 \\
\hline cerebral cyst & 1 & & & 1 & & & & 0 & & & & 0 \\
\hline glioma & & & & 0 & 1 & & & 1 & & & & 0 \\
\hline brain abscess & 1 & & & 1 & & & & 0 & & & & 0 \\
\hline hematoma & & 1 & & 1 & 1 & & & 1 & & & & 0 \\
\hline hemiparesis & & & & 0 & & & & 0 & 1 & & & 1 \\
\hline partial Sz & & & & 0 & 1 & & & 1 & & & & 0 \\
\hline dysphasia & 1 & & & 1 & & & & 0 & & & & 0 \\
\hline DVT & 1 & & & 1 & & & & 0 & 1 & & & 1 \\
\hline PE & & $1 \dagger$ & & 1 & & & & 0 & & & & 0 \\
\hline total & 5 & 2 & 0 & 7 & 4 & 0 & 0 & 4 & 3 & 0 & 0 & 3 \\
\hline
\end{tabular}

* $\mathrm{LT}=$ life threatening; Sz = seizure; VPR = vascular pseudoaneurysm rupture; $\mathrm{WI}=$ wound infection.

$\dagger$ Occurred when the patient was taken off study; this was not a serious adverse event as determined by the institutional review board. 
TABLE 9: Nonserious adverse events seen in the study, by dose level

\begin{tabular}{|c|c|c|c|c|c|c|c|c|c|}
\hline \multirow[b]{2}{*}{ Toxicity } & \multicolumn{3}{|c|}{ Yellow } & \multicolumn{3}{|c|}{ Blue } & \multicolumn{3}{|c|}{ White } \\
\hline & Mild & Mod & Subtotal & Mild & Mod & Subtotal & Mild & Mod & Subtotal \\
\hline balance disorder & 1 & & 1 & & & 0 & & & 0 \\
\hline dizziness & 1 & & 1 & & & 0 & & & 0 \\
\hline headache & & 2 & 2 & 2 & & 2 & 1 & & 1 \\
\hline confusional state & & & & & & & 1 & & 1 \\
\hline hemiparesis & & & 0 & 1 & & 1 & & & 0 \\
\hline partial Sz & 1 & & 1 & & 1 & 1 & & & 0 \\
\hline speech disorder & 1 & & 1 & & & 0 & & & 0 \\
\hline vision blurred & & & 0 & 1 & 1 & 2 & & & 0 \\
\hline DVT & & & 0 & & & 0 & & 1 & 1 \\
\hline total & 4 & 2 & 6 & 4 & 2 & 6 & 2 & 1 & 3 \\
\hline
\end{tabular}

at the probe entry site more than 9 months after LITT. This mass was removed surgically without complication. Although rare, there are previous reports of gliomas developing (progressing) both along surgical routes and epicranially.,14,15 It is not possible to predict or assess the future likelihood of such tumor seeding events as a direct result of the NeuroBlate procedure. However, prudence suggests that in future the patients treated with LITT be appropriately monitored for site-distant progression, especially along the probe trajectory, as is suggested for other needle-based interventions involving aggressive malignancies. ${ }^{14}$ Whereas many of the cases were treated by lasing from the deep to the superficial aspect of the tumor, in the future it may be advantageous to perform the lasing from superficial to deep, thereby sterilizing cells in contact with the probe.

Deep vein thrombosis and PE were reported in 3 and 1 patients, respectively, and were not thought to be directly attributable to the procedure or device (the patients had risk factors or history of DVT). The patient in whom PE was diagnosed was off study at the time of the event, and this was deemed not to be a severe adverse event. Patients with rGBM are known to be at risk for DVT, ${ }^{9}$ and because the postprocedure hospitalization from NeuroBlate is expected to be $<48$ hours we do not believe that this should lead to any significant increase in venous thromboembolic disease. Prophylaxis for DVT (pneumatic compression stockings) was used in these cases; it is the standard of care at both participating institutions.

\section{Observations Regarding the Procedure}

In the present study, NeuroBlate appears to be a safe and a well-tolerated procedure. Unless complications occur, patients can be safely discharged after $24-48$ hours without significant pain in the surgical area, nausea, or headache. No infections related to the procedure were seen in this study within 6 months of treatment. As with all surgical ablative procedures, NeuroBlate is limited to the margins of the treatment area defined by the surgeon. For highly infiltrative tumors, such as GBM, surgical intervention will not eliminate tumor cells that have diffused through the brain separate from the tumor mass itself. However, local control of the tumor mass is generally
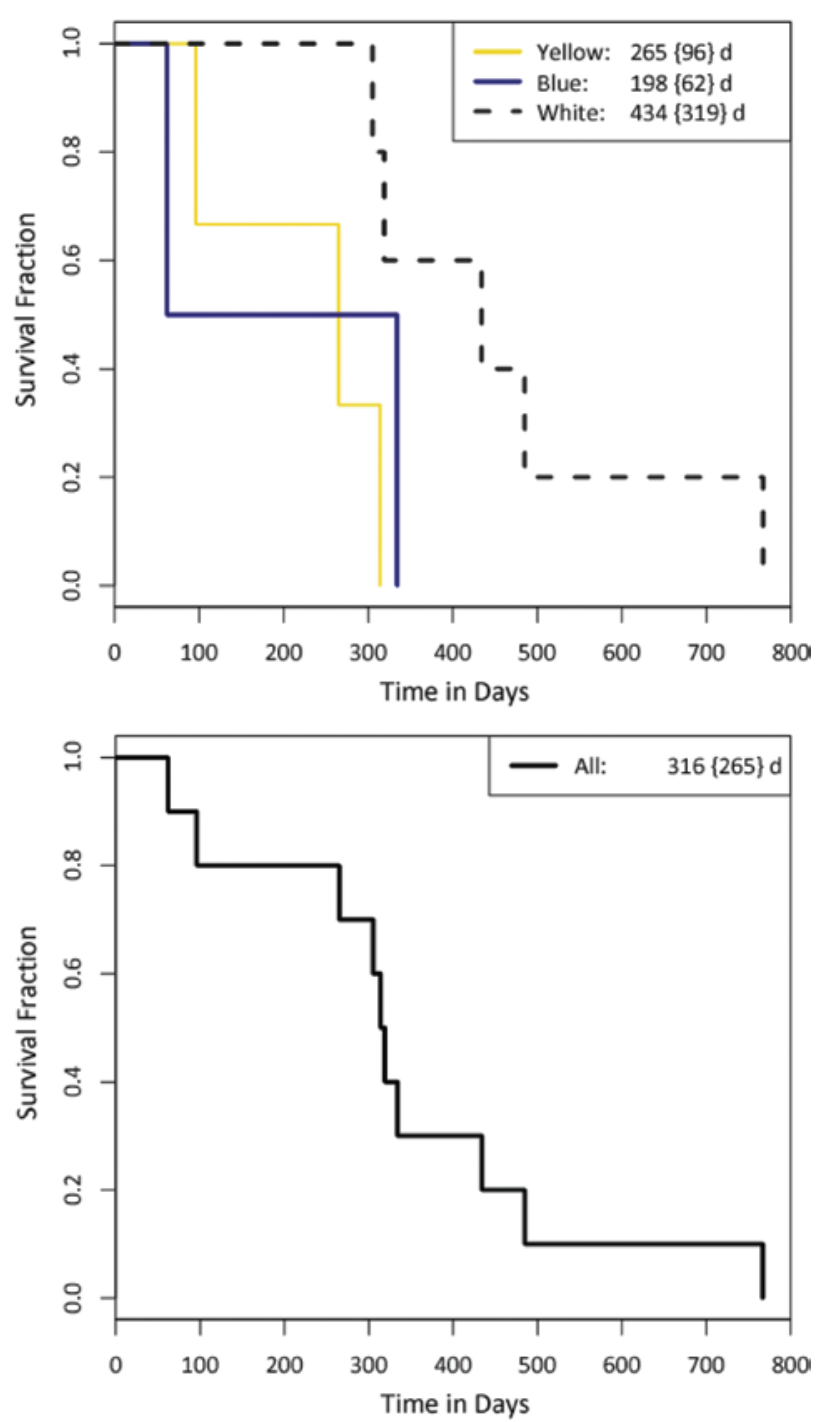

Fig. 9. Kaplan-Meier survival curves of NeuroBlate first-in-humans trial for rGBM, by thermal dose level (upper) and for all participants (lower). The colors of the survival curves indicate the dosage levels, with corresponding median survival and lower limit of confidence interval for the curves indicated in the key (the upper confidence limit was not reached). $d$ = days. 
the first objective of treatment in a craniotomy as well as in a NeuroBlate case. NeuroBlate may be particularly helpful in controlling the edema, mass effect, and other deleterious effects of malignant brain tumors.

The minimally invasive nature and interactive surgical control of the NeuroBlate procedure, coupled with the advantages of real-time MRI monitoring, suggests utility in treating brain tumors in which margins are best determined by MRI or in which resection is preferred, but not completely feasible or practical. It may also be useful to treat certain patients who might otherwise be poor candidates for surgery or SRS due to tumor location or size limitations. Additionally, the nature of laser energy leads to extensive tumor cell death within 48 hours and may have benefit in specific cases for which the ionizing energy used in radiation and radiosurgery poses unacceptable risks or fails to rapidly reduce tumor mass effect.

Although this study was limited to patients with rGBMs, NeuroBlate offers a potentially important method of intervention in patients with some low- to high-grade gliomas, whether benign or malignant, as well as benign tumors such as meningiomas, brain metastases, and failures of SRS for brain metastases. The NeuroBlate System received FDA 510(k) clearance on May 1, 2009. Clinical studies are planned or underway to further evaluate NeuroBlate for rGBMs as well as other malignant tumors and for failed radiosurgery for brain metastases (recurrent tumor and radiation necrosis).

\section{Conclusions}

The NeuroBlate Thermal Therapy System appears to provide a novel and minimally invasive approach for treating deep hemispheric rGBM. This brain tumor therapy represents a significant advance over historical attempts at LITT and is facilitated by real-time thermography and software that accurately predict thermal damage. The regulatory issue that limited the number of trajectories is no longer active. Technical issues that limited the range of motion of immobilization devices and also the MRI coil design that limited access in this trial are currently being addressed. Vascular studies and DTI tractography should be incorporated into the treatment process in selected cases. NeuroBlate holds the promise of enabling the delivery of thermal ablation in real time with surgical precision in some patients with brain tumors in whom safe, conventional surgery is impractical or impossible.

\section{Disclosure}

Drs. Sloan, Ahluwalia, Barnett, and Torchia are paid consultants for Monteris Medical, Inc., and Dr. Ahluwalia is also a consultant for Elekta. All consultation agreements conform to the standards set by the authors' respective institutions for conflict of interest, and none have an equity interest in Monteris Medical or any other LITT company. Drs. Barnett and Sloan, and Monteris Medical, Inc., sponsored the study. Dr. Barnett was supported, in part, by the Rose Ella Burkhardt endowment. Dr. Sloan was supported, in part, by the Peter B. Cristal Chair in Neurosurgical Oncology and the Kimble Foundation Fund for Neuro-Oncology in honor of Steven Kimble. Drs. Griswold and Sunshine receive support from Siemens Medical for non-study-related clinical or research efforts that they oversee. Dr. Phillips received salary support from Monteris, which also paid for MRI time. Dr. Ahluwalia is a member of the speaker's bureau for Merck.

Author contributions to the study and manuscript preparation include the following. Conception and design: Barnett, Sloan. Analysis and interpretation of data: Barnett, Sloan, Ahluwalia, Valerio-Pascua, Manjila, Jones, Sunshine, Phillips. Drafting the article: Barnett, Sloan, Ahluwalia, Valerio-Pascua, Manjila. Critically revising the article: all authors. Reviewed submitted version of manuscript: all authors. Approved the final version of the manuscript on behalf of all authors: Barnett, Sloan. Administrative/technical/ material support: Torchia, Jones, Griswold, Clampitt. Study supervision: Barnett, Sloan. Patient care: Barnett, Sloan, Valerio-Pascua, Manjila, Torchia, Brewer, Jochum, McGraw, Diorio, Ditz.

\section{Acknowledgment}

The authors thank Christine Moore for her assistance with the preparation of this manuscript. 
A. E. Sloan et al.

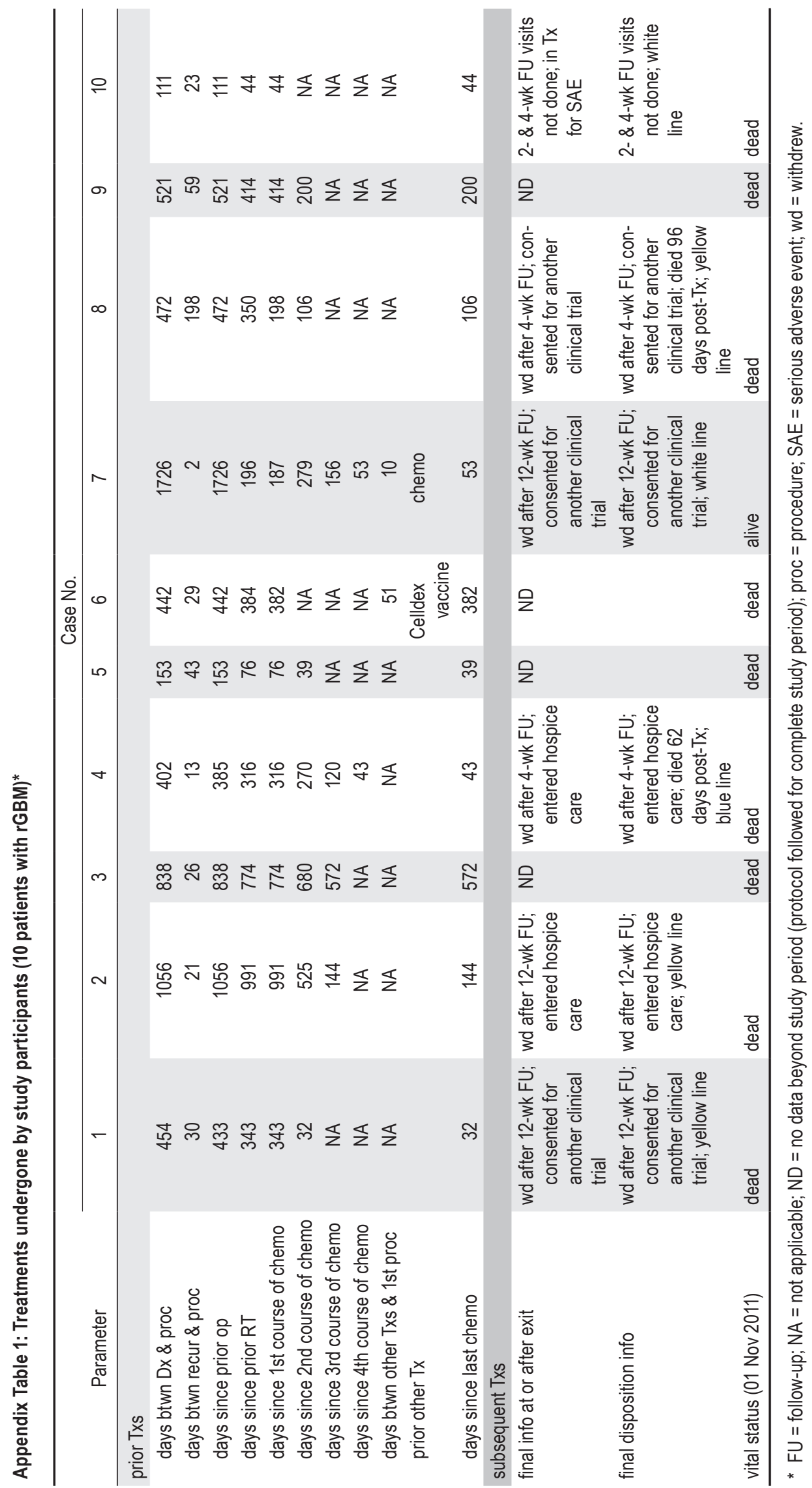




\section{References}

1. Barker FG II, Chang SM, Gutin PH, Malec MK, McDermott MW, Prados MD, et al: Survival and functional status after resection of recurrent glioblastoma multiforme. Neurosurgery 42:709-723, 1998

2. Beaumont TL, Kupsky WJ, Barger GR, Sloan AE: Gliosarcoma with multiple extracranial metastases: case report and review of the literature. J Neurooncol 83:39-46, 2007

3. Carpentier A, McNichols RJ, Stafford RJ, Itzcovitz J, Guichard JP, Reizine D, et al: Real-time magnetic resonance-guided laser thermal therapy for focal metastatic brain tumors. Neurosurgery 63 (1 Suppl 1):ONS21-ONS29, 2008

4. Chen AM, Chang S, Pouliot J, Sneed PK, Prados MD, Lamborn KR, et al: Phase I trial of gross total resection, permanent iodine-125 brachytherapy, and hyperfractionated radiotherapy for newly diagnosed glioblastoma multiforme. Int J Radiat Oncol Biol Phys 69:825-830, 2007

5. Ivanova A, Montazer-Haghighi A, Mohanty SG, Durham SD: Improved up-and-down designs for phase I trials. Stat Med 22:69-82, 2003

6. Kahn T, Bettag M, Ulrich F, Schwarzmaier HJ, Schober R, Fürst G, et al: MRI-guided laser-induced interstitial thermotherapy of cerebral neoplasms. J Comput Assist Tomogr 18: 519-532, 1994

7. Kahn T, Harth T, Kiwit JC, Schwarzmaier HJ, Wald C, Mödder U: In vivo MRI thermometry using a phase-sensitive sequence: preliminary experience during MRI-guided laserinduced interstitial thermotherapy of brain tumors. J Magn Reson Imaging 8:160-164, 1998

8. Kangasniemi M, McNichols RJ, Bankson JA, Gowda A, Price RE, Hazle JD: Thermal therapy of canine cerebral tumors using a $980 \mathrm{~nm}$ diode laser with MR temperature-sensitive imaging feedback. Lasers Surg Med 35:41-50, 2004

9. Kayser-Gatchalian MC, Kayser K: Thrombosis and intracranial tumors. J Neurol 209:217-224, 1975

10. Kondziolka D, Flickinger JC, Bissonette DJ, Bozik M, Lunsford LD: Survival benefit of stereotactic radiosurgery for patients with malignant glial neoplasms. Neurosurgery 41: 776-785, 1997

11. Lacroix M, Abi-Said D, Fourney DR, Gokaslan ZL, Shi W, DeMonte F, et al: A multivariate analysis of 416 patients with glioblastoma multiforme: prognosis, extent of resection, and survival. J Neurosurg 95:190-198, 2001

12. Leonardi MA, Lumenta CB: Stereotactic guided laser-induced interstitial thermotherapy (SLITT) in gliomas with intraoperative morphologic monitoring in an open MR: clinical experience. Minim Invasive Neurosurg 45:201-207, 2002

13. Leonardi MA, Lumenta CB, Gumprecht HK, von Einsiedel GH, Wilhelm T: Stereotactic guided laser-induced interstitial thermotherapy (SLITT) in gliomas with intraoperative morphologic monitoring in an open MR-unit. Minim Invasive Neurosurg 44:37-42, 2001

14. Mentrikoski M, Johnson MD, Korones DN, Scott GA: Glioblastoma multiforme in skin: a report of 2 cases and review of the literature. Am J Dermatopathol 30:381-384, 2008

15. Miliaras G, Tsitsopoulos PP, Markoula S, Kyritsis A, Polyzoidis KS, Malamou-Mitsi V: Multifocal glioblastoma with remote cutaneous metastasis: a case report and review of the literature. Cent Eur Neurosurg 70:39-42, 2009

16. National Comprehensive Cancer Network: NCCN Clinical Practice Guidelines in Oncology (NCCN Guidelines $\left.{ }^{\circledR}\right)$ : Central Nervous System Cancers, Version 1.2013. Fort Washington, PA: NCCN, 2012

17. Reimer P, Bremer C, Horch C, Morgenroth C, Allkemper T, Schuierer G: MR-monitored LITT as a palliative concept in patients with high grade gliomas: preliminary clinical experience. J Magn Reson Imaging 8:240-244, 1998

18. Romanelli P, Conti A, Pontoriero A, Ricciardi GK, Tomasello F, De Renzis C, et al: Role of stereotactic radiosurgery and fractionated stereotactic radiotherapy for the treatment of recurrent glioblastoma multiforme. Neurosurg Focus 27(6):E8, 2009

19. Sanai N, Polley MY, McDermott MW, Parsa AT, Berger MS: An extent of resection threshold for newly diagnosed glioblastomas. Clinical article. J Neurosurg 115:3-8, 2011

20. Sapareto SA, Dewey WC: Thermal dose determination in cancer therapy. Int J Radiat Oncol Biol Phys 10:787-800, 1984

21. Sawaya R, Hammoud M, Schoppa D, Hess KR, Wu SZ, Shi WM, et al: Neurosurgical outcomes in a modern series of 400 craniotomies for treatment of parenchymal tumors. Neurosurgery 42:1044-1056, 1998

22. Schwarzmaier HJ, Eickmeyer F, von Tempelhoff W, Fiedler VU, Niehoff H, Ulrich SD, et al: MR-guided laser-induced interstitial thermotherapy of recurrent glioblastoma multiforme: preliminary results in 16 patients. Eur J Radiol 59:208-215, 2006

23. Schwarzmaier HJ, Eickmeyer F, von Tempelhoff W, Fiedler VU, Niehoff H, Ulrich SD, et al: MR-guided laser irradiation of recurrent glioblastomas. J Magn Reson Imaging 22:799_ 803,2005

24. Schwarzmaier HJ, Yaroslavsky IV, Yaroslavsky AN, Fiedler V, Ulrich F, Kahn T: Treatment planning for MRI-guided laser-induced interstitial thermotherapy of brain tumors-the role of blood perfusion. J Magn Reson Imaging 8:121-127, 1998

25. Selker RG, Shapiro WR, Burger P, Blackwood MS, Arena VC, Gilder JC, et al: The Brain Tumor Cooperative Group NIH Trial 87-01: a randomized comparison of surgery, external radiotherapy, and carmustine versus surgery, interstitial radiotherapy boost, external radiation therapy, and carmustine. Neurosurgery 51:343-357, 2002

26. Shaw E, Scott C, Souhami L, Dinapoli R, Kline R, Loeffler J, et al: Single dose radiosurgical treatment of recurrent previously irradiated primary brain tumors and brain metastases: final report of RTOG protocol 90-05. Int J Radiat Oncol Biol Phys 47:291-298, 2000

27. Sneed PK, Stauffer PR, McDermott MW, Diederich CJ, Lamborn KR, Prados MD, et al: Survival benefit of hyperthermia in a prospective randomized trial of brachytherapy boost +/- hyperthermia for glioblastoma multiforme. Int J Radiat Oncol Biol Phys 40:287-295, 1998

28. Souhami L, Seiferheld W, Brachman D, Podgorsak EB, Werner-Wasik M, Lustig R, et al: Randomized comparison of stereotactic radiosurgery followed by conventional radiotherapy with carmustine to conventional radiotherapy with carmustine for patients with glioblastoma multiforme: report of Radiation Therapy Oncology Group 93-05 protocol. Int J Radiat Oncol Biol Phys 60:853-860, 2004

29. Stupp R, Mason WP, van den Bent MJ, Weller M, Fisher B, Taphoorn MJ, et al: Radiotherapy plus concomitant and adjuvant temozolomide for glioblastoma. N Engl J Med 352:987_ 996, 2005

30. Ulm AJ III, Friedman WA, Bradshaw P, Foote KD, Bova FJ: Radiosurgery in the treatment of malignant gliomas: the University of Florida experience. Neurosurgery 57:512-517, 2005

\footnotetext{
Manuscript submitted January 12, 2012.
}

Accepted January 24, 2013.

Please include this information when citing this paper: published online April 5, 2013; DOI: 10.3171/2013.1.JNS1291.

Address correspondence to: Gene H. Barnett, M.D., M.B.A., The Rose Ella Burkhardt Brain Tumor \& Neuro-Oncology Center, Cleveland Clinic Neurological and Cancer Institutes, Cleveland Clinic/S73, 9500 Euclid Avenue, Cleveland, Ohio 44195. email: barnetg@ccf.org. 